\title{
Digital Twins in Civil Infrastructure Systems
}

\author{
Matthew Callcut ${ }^{1}$, Jean-Paul Cerceau Agliozzo ${ }^{1}$, Liz Varga ${ }^{2, *(\mathbb{D})}$ and Lauren McMillan ${ }^{2} \mathbb{D}$ \\ 1 Department of Civil, Environmental and Geomatic Engineering, University College London, UCL \\ Gower Street, London WC1E 6BT, UK; matthew.callcut.19@alumni.ucl.ac.uk (M.C.); \\ jpcerceau@gmail.com (J.-P.C.A.) \\ 2 Infrastructure Systems Institute, University College London, UCL Gower Street, London WC1E 6BT, UK; \\ lauren.mcmillan.19@ucl.ac.uk \\ * Correspondence: 1.varga@ucl.ac.uk
}

Citation: Callcut, M.; Cerceau Agliozzo, J.-P.; Varga, L.; McMillan, L. Digital Twins in Civil Infrastructure Systems. Sustainability 2021, 13, 11549. https://doi.org/10.3390/ su132011549

Academic Editors: Dragan Komljenovic, Georges Abdul-Nour and François Gauthier

Received: 2 September 2021

Accepted: 14 October 2021

Published: 19 October 2021

Publisher's Note: MDPI stays neutral with regard to jurisdictional claims in published maps and institutional affiliations.

Copyright: (c) 2021 by the authors. Licensee MDPI, Basel, Switzerland. This article is an open access article distributed under the terms and conditions of the Creative Commons Attribution (CC BY) license (https:/ / creativecommons.org/licenses/by/ $4.0 /)$.

\begin{abstract}
This research explores the existing definitions, concepts and applications surrounding the efficient implementation and use of digital twins (DTs) within civil infrastructure systems (CISs). The CISs within the scope of this research are as follows: transportation, energy, telecommunications, water and waste, as well as Smart Cities, which encompasses all of the previous. The research methodology consists of a review of current literature, a series of semi-structured interviews and a detailed survey. The outcome of this work is a refined definition of DTs within CISs, in addition to a set of recommendations for both future academic research and industry best practice.
\end{abstract}

Keywords: digital twin; digital model; infrastructure systems

\section{Introduction}

The engineering industry has long been a pioneer when it comes to leveraging digital solutions to solve problems. However, while many of the existing models and information systems offer a view of the asset or system modelled, they cannot provide insight into how the system works. As a result, when faced with new challenges, civil infrastructure systems (CISs), consisting of energy, transport, water/wastewater, telecommunications and waste systems, are primarily reactive, as opposed to anticipating and acting to prevent potential hazards. Digital twins (DTs), a recent and increasingly popular technique for modelling CISs, are evolving to meet these challenges and overcome the limits of traditional models.

Functioning CISs are essential for the normal operation of society. CISs should be focused on the people for whom they provide crucial services, such as power, transportation and water [1], which are essential for the continuation of economic prosperity in the modern world [2-4]. If fully functioning CISs are essential to an operational society, then their sustainability and efficiency under normal conditions, as well as their resilience following extreme events, are a high priority [5]. More recently, with advances in information and communications technology (ICT), CISs are growing increasingly complex and interdependent, and so should be positioned within the context of a wider 'system of systems' [1-3]. As the focus of this paper, DTs have the potential to help increase the efficiency, sustainability and resilience of CISs by enabling the visualisation and monitoring of these complexities and interdependencies.

The built environment as a whole constitutes $40 \%$ of total $\mathrm{CO}_{2}$ emissions in the UK [6]. In order to meet the IPCC's targets of halving anthropogenic $\mathrm{CO}_{2}$ emissions by 2030 and achieving net zero by 2050, the management of resources and operation of infrastructure need to be far more efficient [7]. With digitalisation, one of the most powerful interventions in the pursuit of sustainability, disruptive digital approaches such as DTs will be valuable tools. The 'right time' collection of infrastructure data through DTs will enable stakeholders to reduce emissions, make sustainable (renewable energy-oriented) choices for infrastructure services, and manage climate resilience proactively. 
The concept of DTs as the next generation in the evolution of digital problem-solving techniques has recently gained a lot of traction within academia and across a wide range of industries. The DT market value is expected to be in excess of USD 35 billion by 2025 [8], with Gartner predicting in 2017 that "by 2021, half of large industrial companies will use digital twins, resulting in those organisations gaining a $10 \%$ improvement in effectiveness" [9]. To facilitate the effective adoption of DTs, this paper seeks to discover the key characteristics that define a DT, identify some of the potential barriers to uptake, and explore what further knowledge must be developed to support the effective introduction of DTs throughout CIS. Applications demonstrating effective implementation of DTs are also identified from each infrastructure sector and within the broader setting of 'smart cities'.

To accomplish the stated aims of this paper, the content will be structured as defined below:

Theoretical Background-An introduction to the theory of digitalisation.

Research Methodology-An overview of the methods used to obtain the information presented in 'Results'.

Literature Review-This section examines the origins of DTs, their use to date in CISs, and the enabling technologies which have the potential to support the implementation of DTs.

Results-A presentation of various DTs and their current or proposed applications within CISs, and the results of a survey and one-to-one interviews on professionals' opinions regarding DTs.

Discussion-A wide-ranging discussion on the definition of a DT, barriers to implementation, and the future of DTs in industry.

Conclusions, Limitations and Recommendations-The key contributions of this paper are presented, along with recommendations for future research on DTs.

\section{Theoretical Background}

Digitalisation is a general-purpose innovation, concerned with gathering information on physical objects and converting this into a digital representation that can be processed automatically. The digitalisation of infrastructure systems is the driving force behind smart infrastructure. The growth in digitalisation is both enabled and accelerated by advances in other technologies, such as machine learning and micro sensors. The ways in which data are produced and processed have changed dramatically in recent decades. Manually generated data come at a high cost. New techniques have automated the data production process, lowering the cost of digitalising pre-existing data and allowing infrastructure managers access to a wealth of new data through the integration of sensors into infrastructure systems. The 'Internet of Things', for example, has the power to digitalise a massive range of activities, from waste management to structural health monitoring $[10,11]$.

Shifts in governance structures and pressure to decarbonise have resulted in a drive towards greater convergence across infrastructure sectors, moving away from the traditional siloed approach to infrastructure network management. A pervasive process, digitalisation is not focussed on any specific activity, but on the coordination of many activities. Similarly, the core digital processes of data generation, transmission, storage and analysis are not specific to any infrastructure sector. Thus, digitalisation has the potential to accelerate convergence in infrastructure networks, enabling cross-sector platforms that coordinate previously uncoordinated activities, thereby improving efficiency at the system level. These efficiency gains, and associated cost reductions, go beyond day-to-day operations, extending to maintenance, planning and construction of infrastructure systems [12].

Digitalisation not only enables optimisation of existing operations, but also the reorganisation of entire supply chains, facilitated by lower manufacturing costs and improved coordination. For example, new automated technologies drive a shift from 'task-by-task' supply chains to a vertically integrated production model [13]. Digitalisation can also lead to the emergence of new services. Often driven by commercial benefits, these new services can also benefit social and environmental objectives. For example, digital technology in the road sector can save consumers time, through congestion warnings and road planning, and 
money, by helping them to avoid toll roads, but can also be beneficial in accident reduction and pollution monitoring [12].

During the design and construction phase, digital technologies can reduce both costs and project delivery time through automation and coordination. Building information modelling (BIM), for example, enables information to be shared between stakeholders and coordinates activities across teams to optimise the design and build process $[14,15]$. Once an asset has been built, advances in sensing technology have the ability to transform how maintenance is performed, moving from a corrective approach, which deals with an issue once it is detected, to a conditions-based approach, which tailors the maintenance strategy to the real state of system components [16]. Such an approach allows for a more rapid detection of faults or potential faults and a significant reduction in maintenance costs. Digitalisation can also enable more active infrastructure management through the control of supply and demand capacities. This is made possible through the ability to obtain granular flow data across the network, data which are gathered by new digital technologies. Machine learning techniques can assist in interpreting this data, offering insights into how to best respond to changes in the system. This can help avoid failures in the network, or act to mitigate failure and restore functionality [14].

There are challenges that must be overcome, however, if the full potential of digitalisation is to be realised. These include technical challenges, such as issues with data accuracy, sharing, security, and standardisation, and non-technical challenges such as digital literacy, usability, and deployment [17].

\section{Research Methodology}

\subsection{Research Design}

This study combines an analysis of literature findings with interviews and a survey in order to establish a comprehensive picture of opinions on DTs in research and industry. Figure 1 shows each stage of the research process.

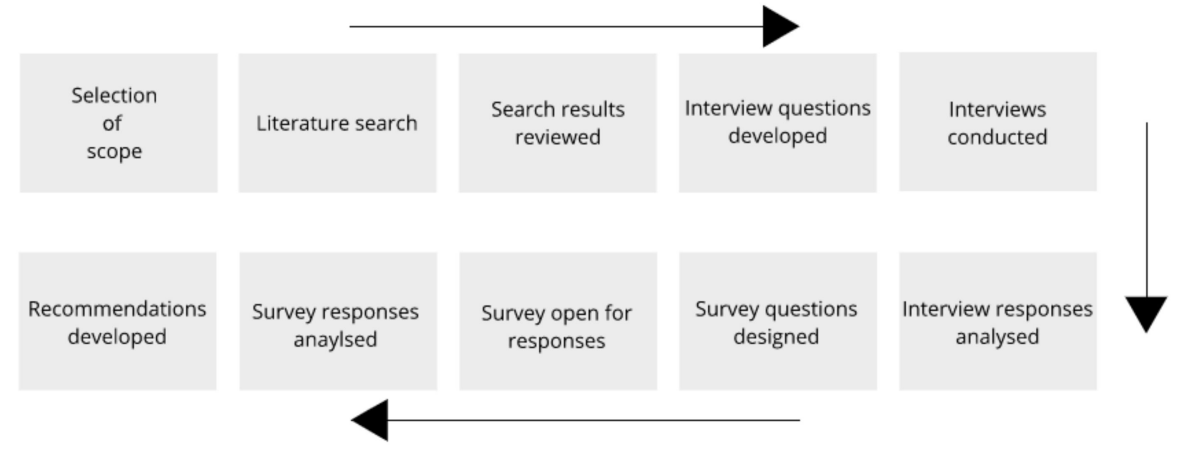

Figure 1. Research process.

\subsection{Data Collection}

\subsubsection{Literature Search}

Preliminary research revealed that knowledge on DTs, as a new and evolving concept, is limited, fragmented, and dispersed across the literature of the several related infrastructure sectors. For these reasons, an exhaustive search of DT literature for each sector was undertaken as a foundation for decisions as to subsequent methods that would seek to supplement the areas where the literature is underdeveloped, and to inform the building of an agenda for future academic research and actions of industry and government. Examples of the keywords chosen are as follows, with the number of search results shown in brackets:

- Transportation (345)-Transport, Rail, Highway, Shipping

- $\quad$ Energy (223)-Energy, Smart grid, Renewable, Nuclear

- Water (54)-Water, Sewage, Irrigation

- Telecommunications (51)-Telecoms, Smartphone, 5G, Satellite 


\section{- $\quad$ Smart Cities (51)-Smart City}

The publication year and number of citations were used to sort the initial selection of papers. After screening for relevance, each paper had to meet further quality criteria, including peer-review and the absence of any obvious or stated biases.

Following this search, grey literature such as reports, white papers, and unpublished work from research organisations and industry was also sought out. Grey literature, although not peer-reviewed and potentially biased, shows the perspective of those implementing and working with DTs within industry.

The findings in the literature highlighted research gaps and the lack of consensus around what constitutes a DT. In order to fill these gaps, a survey of industry experts was undertaken, the direction of which was informed by more detailed one-to-one interviews with industry informants.

\subsubsection{Interview Process}

Six one-to-one interviews were conducted in August 2020, with an additional brief correspondence from a seventh interviewee. Although all interviewees are presented anonymously in this paper, they comprise stakeholders from a variety of backgrounds and levels of experience with DTs. This was conducted with the intention of selecting interviewees which represent a diverse range of opinions across industry and academia.

The objective of these interviews was to initiate a discussion around the main focal points of this paper and gain insights from differing perspectives. These interviews were semi-structured, with eight set questions posed to respondents, as listed below:

1. How would you define a digital twin?

2. Could you describe the digital twins that you have experience with?

3. Can you think of any other potential-use cases of digital twins within infrastructure systems that, as far as you are aware, are not currently being explored?

4. Do you think any particular area surrounding digital twins needs more research?

5. Are there any regulatory concerns regarding the use of digital twins within the UK?

6. What are your thoughts on the awareness of digital twins within the industry in general?

7. What is the UK Government doing with regard to DTs?

8. Do you have any further comments?

A semi-structured approach, with non-leading questions, allowed interviewees to drive the conversation in whatever direction they felt most relevant. A laddering interview technique was also utilised to elicit extended explanations where appropriate.

Transcripts of each interview were analysed, highlighting key terms and sentences and annotating them to identify important concepts and to link ideas together. Each of the transcripts was then coded into a Microsoft Excel sheet to extract key insights and opinions, codified within specific themes. Significant opinions could comprise surprising content, recurring concepts, or reinforcement of concepts found in the literature.

\subsubsection{Survey Instrument}

Members of the DT community were approached and asked to complete a survey in order to better understand the current state of DT knowledge and development. The respondents consisted of publishers of academic papers as well as members of the Centre for Digital Built Britain. The population of such experts is small because the use of DTs in civil infrastructure is in its infancy. There were 30 valid responses recorded, providing a sound sample, but there remains a lack of coverage in certain sectors. This may be due to limited involvement from professionals in those sectors in the wider DT community. All survey responses were recorded from November 2020 to May 2021. The survey consisted of both qualitative and quantitative questions. Participants were asked whether they had created or worked with a DT, which infrastructure sector this DT was for, and what the specific purpose of this DT was. Respondents were then provided with a list of statements regarding the characteristics that define a DT, such as 'Digital twins can only model existing 
objects, so you cannot have a digital twin of a design.' and asked to what extent they agreed with each statement. A similar list of statements was also provided regarding the governance of DTs, such as 'Digital twins should be centrally governed', and respondents were again polled on their agreement with each. Four existing definitions of DTs, from various industry sources, were then described, with respondents asked to rank these from best to worse. Finally, respondents were presented with a list of potential challenges to the development of DTs-including the lack of an agreed-upon definition, the need for regulation, and concerns around data quality, security, and access-and asked to rate each challenge on a scale from 'no challenge' to 'major challenge'.

\subsection{Data Analysis}

This paper draws on data from three sources: a review of academic and grey literature, six interviews with knowledgeable stakeholders, and survey results from 30 participants from the DT community. The findings from each were analysed separately and used to inform the direction of the following stage of the study. Thus, interview topics were guided by the results of the literature search, and survey content was informed by the content of both the literature and interviews, in an iterative process. This allowed the guiding themes of the research to develop naturally. The findings of each stage were then compared, to establish similarities and conflicts between the content of literature and the opinions of those working in the field of DTs.

\subsection{Methodological Limitations}

\subsubsection{Literature Collection and Selection}

The literature collection process was limited to Elsevier Scopus. Although a single database search has the potential to omit valuable knowledge, Scopus was chosen for its rigorous quality criteria, which places peer-review at the centre of the selection process. To minimise the risk of missing important findings, forward and backward citations were followed, and the literature search was only deemed complete once findings had achieved a significant degree of saturation, with additional results becoming increasingly less relevant. A future study could include other databases that offer academic papers not currently available within Scopus. Additionally, although it was intended to choose papers with a high number of citations for the sake of credibility, the limited amount of literature meant that sometimes papers with limited citations were chosen for analysis.

When searching for literature, the key term 'digital twin' has only come into widespread usage in the past five or so years [18], so sources which may utilise DT methodology, but do not feature the DT keyword, will not appear in searches. In contrast, the literature search was also hindered by the lack of clarity around DTs and what they are, so a large portion of time was spent briefly reviewing papers which had nothing to do with the subject of this paper but came up as being relevant because they mentioned DT as a buzzword.

\subsubsection{Survey Data and Analysis}

When searching for correlations by infrastructure sector, survey results were selected for discussion based on a majority opinion. For sectors with a small sample of respondents, it would be inaccurate to conclude that their opinions are representative, even if responses agreed with each other. Similarly, it would be difficult to accurately pinpoint an anomaly if responses were mixed. This suggests the need for future research targeting individual sectors, and a greater sample size within sectors. Nevertheless, from the analysis of survey results against the literature, it was observed that recurring themes came up consistently irrespective of sector, allowing for the general consensus to be extracted from the survey.

Finally, there were no survey results for the telecommunications and waste management system sectors. A future study could include respondents from these sectors. However, the discussion on these sectors showed that the literature concerning these sectors could be slightly behind the more prominent infrastructure systems, as little discussion regarding regulations, data challenges, or data protection was observed. 


\section{Results}

\subsection{General Findings}

\subsubsection{Defining a Digital Twin}

Originally conceptualised in 2002 to optimise product lifecycle management, the first hypothesised DT consisted of a digital informational construct of a physical system that could be created as its own entity and linked with the physical system throughout its lifecycle [19]. This idea of creating a digital representation of a system was furthered by NASA in attempts to optimise lifecycle phases of projects such as sustainable space exploration [20] and the operation of vehicles [21]. Relevant literature over the years suggests that this primary concept remains unchanged. However, inconsistent formal descriptions of DTs prompted ARUP to pool together several definitions from industry experts including IBM, Siemens, and Microsoft, as well as research bodies such as NASA and the Cambridge Centre for Digital Built Britain, to define a DT as "the combination of a computational model and a real-world system, designed to monitor, control and optimise its functionality. Through data and feedback, both simulated and real, a DT can develop capacities for autonomy and to learn from and reason about its environment" [22]. This definition exposes an inherent quality of DTs which hinders a comprehensive definition from being established, which is their ability to evolve over time as more data inputs are connected to the system. It has been argued that gradually scaling up DTs over time is the most suitable approach for enablement, as high upfront costs and the daunting notion of complicated interconnected systems can make companies hesitant to integrate this technology into projects when, in reality, a relationship facilitated through a feedback loop is essentially what generates the twin [23]. Throughout an asset's lifetime, it can be fed more data inputs, which will reveal benefits over time as part of the DT's evolution. The authors of [24] also highlight this key relationship and provide important distinctions between digital models, digital shadows, and digital twins to clear up misconceptions about this technology;

- A digital model features no automatic data exchange between physical and digital objects

- A digital shadow only offers a one-way data flow from the physical to the digital object

- A digital twin embraces data exchange in both directions between physical and digital objects [25].

\subsubsection{Enabling Digital Methods}

Whilst the engineering field has defined the 'why' of DTs and their use within CISs, the discipline of computer science offer solutions as to 'how' DTs can see widespread development and implementation. One reason DTs have been gaining momentum in recent years is the increasing usage of various enabling technologies. Whether the use of all, some, or any of these technologies is integral to the definition of a DT is discussed later in the paper. However, each of these enabling technologies provide context for the environment in which DTs are developed and operated and are therefore explored briefly below.

- Internet of Things (IoT)

The 'Internet of Things' (IoT) has seen sensors integrated into many relatively mundane and conventional physical objects, to connect them to the internet and to each other. It is the "diminishing size, constantly falling price and declining energy consumption" of various electronic components that make the possibility of an abundance of these 'smart' objects a reality [26]. The implementation of IoT devices is already very pervasive. As of 2018 , there were approximately 7 billion IoT devices in operation, with that figure expected to grow to 21 billion by 2025 [27].

\section{- Big Data Analytics}

Big data analytics is commonly used to analyse very large datasets obtained from a range of sources, such as sensors, using either structured or unstructured data, collating this information in a useful way [28].

- Machine Learning 
Machine learning (ML) is a form of artificial intelligence (AI) that enables a system to learn from a dataset, called training data, without being programmed by a human. ML is somewhat similar to big data analytics in that it utilises algorithms that iteratively learn from data to generate useful analysis and insight [29]. ML can then utilise pattern spotting to predict future hazards and develop new solutions to further optimise the system [30].

- Cloud and Edge Computing

Cloud computing is the concept of providing computational and storage services to local devices using a data centre connected via the internet. The benefits of cloud computing are seen when the data reach the data centre and can be analysed. However, transmission of data has a high monetary cost, and can suffer from both excessive delays and security concerns [31]. This is where edge computing can step in. Edge computing is essentially a cloud computing intermediary, whereby some of the services which would take place in the cloud are conducted in a location closer to where the data are collected, at the 'edges' of the network. This physical proximity to data collection addresses the issues of cloud computing described above, without resorting to a dated on-device processing model [32].

\subsection{Sectoral Findings}

Findings from the literature show that, although the characteristics of DTs are in essence very similar throughout different sectors, research into their applications has typically been siloed by sector. Examples for applications of DTs were found in every CIS sector except telecommunications. The same methodology was used to obtain literature as in every other sector, so the reason for this is unclear. However, it is assumed that similar use cases to other sectors would arise, as those DT use cases found in the literature are typically applicable to a wide range of applications at various scales. As explored in survey results, several respondents felt their work with DTs spanned several sectors, and so when rendering a conclusion, it may be inaccurate to infer that it is sector specific. From the applications found in each sector, use cases were identified and have been tabulated in Table 1.

Table 1. Use cases identified from applications identified in literature search.

\begin{tabular}{|c|c|c|c|c|}
\hline Sector & Application & & Use Case & \\
\hline \multirow[b]{2}{*}{ Water } & \multirow{2}{*}{ [33] } & Anomaly Detection & Demand Forecasting & Emergency Planning \\
\hline & & $\begin{array}{l}\text { Maintenance } \\
\text { Scheduling }\end{array}$ & $\begin{array}{l}\text { Operational } \\
\text { Optimisation }\end{array}$ & Predictive Maintenance \\
\hline \multirow{3}{*}{ Energy } & [34] & Predictive Maintenance & & \\
\hline & [35] & Anomaly Detection & $\begin{array}{c}\text { Operational } \\
\text { Optimisation }\end{array}$ & Service-life Forecasting \\
\hline & [36] & Anomaly Detection & $\begin{array}{l}\text { Operational } \\
\text { Optimisation }\end{array}$ & Security Resilience \\
\hline \multirow{3}{*}{ Rail } & $\begin{array}{l}\text { Alstom and } \\
\text { AnyLogic [37] }\end{array}$ & Emergency Planning & $\begin{array}{l}\text { Maintenance } \\
\text { Scheduling }\end{array}$ & Timetable Optimisation \\
\hline & $\begin{array}{c}\text { Atkins and Etihad } \\
\text { Rail [38] }\end{array}$ & Predictive Maintenance & & \\
\hline & $\begin{array}{c}\text { Greater Anglia and } \\
\text { Toshiba [39] }\end{array}$ & Anomaly Detection & Timetable Optimisation & \\
\hline
\end{tabular}


Table 1. Cont

\begin{tabular}{|c|c|c|c|c|}
\hline Sector & Application & & Use Case & \\
\hline \multirow{4}{*}{$\begin{array}{c}\text { Highways and } \\
\text { Autonomous Vehicles }\end{array}$} & Google Maps [40] & $\begin{array}{l}\text { Operational } \\
\text { Optimisation }\end{array}$ & & \\
\hline & Highways England [41] & $\begin{array}{c}\text { Construction Process } \\
\text { Optimisation }\end{array}$ & & \\
\hline & [42] & Route Forecasting & & \\
\hline & $\begin{array}{l}\text { SAVe project, } \\
\text { Germany [43] }\end{array}$ & Scenario modelling & & \\
\hline \multirow{2}{*}{ Bridges } & {$[44]$} & Anomaly Detection & Service-life Forecasting & \\
\hline & [45] & Anomaly Detection & & \\
\hline \multirow{3}{*}{ Smart Cities } & Virtual Singapore [46] & Emergency Planning & $\begin{array}{l}\text { Operational } \\
\text { Optimisation }\end{array}$ & Planning Optimisation \\
\hline & $\begin{array}{l}\text { Newcastle University } \\
\text { and Northumbrian } \\
\text { Water [47] }\end{array}$ & Emergency Planning & & \\
\hline & [48] & City-level Forecasting & Policy Development & Planning Optimisation \\
\hline
\end{tabular}

The most common use cases tend to revolve around forecasting, maintenance, optimisation and planning. Every one of these is ultimately attempting to improve the performance of operational systems.

Upon completion of a rudimentary analysis of these use cases, it was found that they essentially fall into two categories: futures assessment, which involves looking at possibilities further in the future; and operations management, which involves increasing efficiency on more of a short-term basis. The distinction between these two categories is very basic and exists on a temporal scale. However, the ways in which a DT can utilise technologies to be effective in both of these categories varies wildly. It is for this reason that DTs will be more beneficial when used in an operations management context, as the insights generated for a shorter temporal scale will have much greater certainty, and therefore provide a much greater value. This is especially true when, as explored in the discussion section, questions surrounding uncertainties in DTs are considered.

\subsubsection{Digital Twins in Smart Cities}

Similar to those of DTs, smart city definitions in the literature have evolved over time, and there is not yet a widely accepted formal definition [11]. Some sources place an emphasis on sustainable development planning, while more recent definitions highlight high levels of digital interconnectivity, which allows for the use of big data to improve transparency and governance [49]. Cities are complex systems, whose challenges are being addressed through 'smart' innovative information and communications technologies such as autonomous driving, smart energy grids, and digitisation of administrative tasks [50]. A 'smart city' is essentially a large-scale version of a DT that utilises IoT technology in an attempt to connect and map an entire city to its digital counterpart. Ultimately, a smart city must feature technical innovations that are people-centred and aim to improve quality of life, with planning solutions taking a holistic view that considers economic, social and environmental perspectives.

The shift towards an increasingly digital society can enable greater insight into the interactions between humans and infrastructure, particularly the interdependencies that exist across time and space [51]. Disasters can expose interdependencies by stressing community systems. For example, a hurricane could force a portion of a community to evacuate, diminishing the size of the available construction force, thereby reducing both the number of rebuilt homes and the number of people who can return to their homes [49]. This could result in a reduction in tax money allocated to workforce recovery, further hindering 
the rebuilding of homes. Effective disaster management therefore calls for a holistic perspective which considers a community's systems and interactions among systems and the wider population [49]. Future interdependencies between humans, infrastructure, and technologies will be created by an increase in population size and urbanisation, differing from those observed today [51]. If a smart growth agenda is not pursued, poor management decisions arising from uncertainties and unreliable predictions will be inevitable.

It is projected that the market value of smart cities will surpass USD 2376 billion by 2025 [50]. Consequently, the potential for DTs to contribute to smart city development is increasing year on year, due to rapid advancements in connectivity through the IoT [24]. The integration of sensors within infrastructure systems is of great value for futureproofing, as it allows for improved monitoring, control, and decision making, through enhanced visualisation and interaction with city data [52]. DTs can act a testbed to simulate scenarios and can also learn from the environment by analysing changes in the data collected [24]. The quality of prediction relies on a combination of real-time and aggregated historical performance in human-infrastructure systems. Widespread adoption of DT technology will allow for an understanding of how smart cities will perform under various economic, environmental, and social conditions, pre-emptively identifying the drivers of possible disruptions [51].

Virtual Singapore is an example of a DT being used to replicate an entire city. In a collaboration with Dassault Systèmes, the Singaporean Government has created a 3D model of the city, which is supported by static data as well as dynamic data from a pervasive set of sensors. The result of this effort is a system which enables urban planners, engineers and architects to simulate solutions to the city's problems without actually implementing them, which can include, but is not limited to [46]:

- Calculating how much energy could be generated by installing solar panels on a particular building's roof.

- Disaster management, to help develop and optimise evacuation models.

- Automate planning processes based on detailed building information of the city, in addition to other relevant datasets.

- Evaluate infrastructure designs and construction management plans with respect to existing infrastructure and dynamic data.

A research plan has been set out for the implementation of a DT for the region surrounding Cambridge, UK [48]. This aims to model interdependencies and help bridge the gap between current policy silos, enabling a collaborative approach to future development scenarios. The authors determine two key themes which tie infrastructure sectors together: the future location of housing, businesses and employment and the transportation choices that people make to commute between them.

Included in this plan are three key tasks which encompass the DT methodology:

- Task 1-Use historic data to understand and identify how people commute to and from work and the key factors that influence this decision.

- Task 2-Design future scenarios of various different paths that future infrastructure development can take.

- Task 3-Combine outputs from the DT with current local authority models on systems such as the transport network, energy demand and air pollution.

\subsubsection{Digital Twins in Transport Systems}

Increased urbanisation puts pressure on the efficient management of transport systems. High levels of congestion, delays from inefficient services, commuter frustration and increased carbon emissions are some of the factors prompting authorities to modernise and digitise transport using intelligent systems [53]. These use innovative modelling systems to provide users with more information, increasing the quality of interactions between transport services [54].

There is an existing DT of traffic on highways networks which has been used for many years and is currently in use every day by millions of people: Google Maps. Google 
obtains traffic data anonymously from the real-time location data of smartphone users, in addition to local government traffic information and historical traffic data [40]. The insight and bi-directional connection come from the ability of Google Maps to compute the best route for a vehicle when there is traffic congestion ahead, thereby altering the physical asset itself.

The authors of [55] predict that live as-built DTs will become standard for the construction and maintenance process of highways by 2032-2035. As automation becomes more common in on-site construction work, with trials of new driverless dump trucks on the A14 Cambridge to Huntingdon bypass [41], the presence of survey teams will reduce, as surveying technology is incorporated into autonomous plants. This accelerates the ability to convert sensor data into DTs in the construction process. Another opportunity is the ability to derive training datasets from DTs and the real-world sensor data contained in them, for use in supporting the development of advanced algorithms for AI decision-making in construction [55]. Digitisation can bring huge benefits to road safety. A total of 1.24 million road traffic deaths and 50 million non-fatal injuries occur yearly, and active safety approaches in the form of advanced driver assistance and automation have the potential to reduce these significantly. The 'SAVe' project aims to generate a DT for the urban road network in Ingolstadt, Germany. The purpose of the twin is to perform cheap and risk-free virtual test drives particularly at busy intersections to identify and gain insight into critical scenarios [43].

Simulations to better understand critical scenarios are also present in the aviation industry, where studies into air traffic control systems highlight how vulnerable airports aerial environments can be without effective risk management solutions [56]. The inclusion of DTs in intelligent management systems can mitigate risk and increase system stability. DTs can be used to enhance a centralised airport traffic control system, as in [57], where vehicle coordinates are received up to 10 times per second, and the user is able to observe the real-time displacement of vehicles. This increased visibility can help mitigate negative consequences resulting from dangerous proximity between vehicles and objects, as well as tackling congestion issues stemming from poor management.

Every year, the United States spends around USD 12.8 billion to tackle deteriorating bridge conditions [58]. This is due to major challenges in managing the data and information needed for the effective maintenance of bridges. It is estimated that at least 315,000 bridge inspections are needed annually across the US and the UK. Research into maintenance systems for cable-supported bridges highlights that an effective DT model can allow data to be accumulated during operation so that, in events such as the fractures caused by cable fires at the Seohae Grand Bridge in Korea, experts can tune into stored data and immediately react to incidents with proper judgement [45]. A case study considers two newly built railway bridges in Staffordshire, UK. The authors set out the physical data capture requirements for the successful implementation of a DT, presenting a use case with the aim of better structural health monitoring (SHM) [44]. At the time of their construction, the two bridges were fitted with a fibre optic sensor (FOS) network. The bridge detailed in the paper was a steel half-through bridge with a composite deck, with 291 discrete fibre Bragg grating (FBG) sensors distributed. Utilising the SHM data obtained from the sensors, a DT is proposed which encompasses various techniques: BIM, Finite Element Modelling (FEM) and statistical modelling. This DT is able to:

- Forecast a predicted service life of the bridge.

- Detect anomalies utilising real data measurements.

- Allow lessons to be learnt from the real data measured from the bridge, therefore improving future projects.

Evidence of uncertainty in the definition of DTs can still be found in the literature databases. For example, though [59] discusses the advantages of a DT for the sustainable evaluation of King's Cross station in London, they do not differentiate between a 3D BIM model and a DT, using these terms interchangeably. As such, this work is actually referring to a digital model. In a more developed example in the railway industry, Alstom, 
who operate and maintain the rail fleet of the UK's West Coast Main Line, developed a DT using AnyLogic software. It is possible to see an updated view, utilising daily operational updates, of the current condition of their fleet, including current working hours, maintenance regimes and schedules, and the maintenance capabilities of depots and stations, all in one platform. This was achieved by compiling data from multiple sources and overlaying this on a Geographic Information System (GIS) map. This DT allows Alstom benefits which they would not otherwise have had [37]:

- The ability to explore various maintenance regimes digitally and without consequence.

- The capability to run what-if scenarios to develop response plans for events, such as emergencies or the introduction of new timetables, and to anticipate how these events may affect maintenance requirements.

\subsubsection{Digital Twins in Water Systems}

Urban water systems are complex, with a large extent of components residing underground. These are difficult to monitor during operation and, in the event of failure, complicated to repair [60]. Further complexity arises from fluctuations in rainfall and the fact that surface runoff depends on past weather events as well as population growth, resource scarcity and infrastructure wear and tear [33]. While these present challenges to hydrological modelling, supervisor control and data acquisition (SCADA) systems have begun to address these issues in water and wastewater utilities. The next step forward is to introduce widespread use of DTs, enabling dynamic process simulations to improve the design of new facilities, reduce risk and optimise operations [61]. DTs have been present in the water distribution industry for several years, with utility companies such as Global Omnium in Spain, Anglian Water in the UK, and Halifax in Canada implementing this technology, primarily for the purpose of reducing water leakage through prediction of pipe failures [60].

DTs can be implemented within all types of water infrastructure including pumping stations, pipe networks, storage tanks and treatment facilities, as long as precise measurements and calibration are provided, so that the twin accurately reflects the performance of the asset. This enables facility staff to holistically understand the system by evaluating large datasets and identifying underperforming elements such as improperly scaled instrumentation, degraded pump performance, or hydraulic bottlenecks [61]. One of the most significant benefits described in [61] is the DT's ability to be used for failure analysis through simulations of extreme conditions, identifying potential shortfalls or realizing additional unplanned capacity. This work also describes several key characteristics needed for a DT within a water treatment system, one of them being an intuitive graphical user interface. The authors of [61] recognise a DT as a complete system, rather than just a relationship based on automatic data flow.

An example of a use case for a water distribution system (WDS) can be found in [33]. The subject is a DT of the water distribution network for the metropolitan area of Valencia, Spain, which is currently in operation. Supplying water to 1.6 million inhabitants, the whole network has a total of 113,000 pipes, 8 reservoirs, 28 tanks, 47 pumps, 259 regulating valves, 48,500 manual valves, 4600 hydrants, 118,000 service connections, 97 flowmeters and 470 pressure gauges, among other elements. The DT contains a detailed model consisting of 325,000 nodes, which was created using a big data approach of gathering information from multiple sources. However, this model is too detailed to be able to run real-time analyses, and so a less-detailed strategic model, consisting of 10,000 nodes, was derived from the original and is updated with real data every minute.

The DT has the ability to forecast decisions before making them, analyse the impacts of past events on the system, and program actions to be carried out within the next $24 \mathrm{~h}$. This has multiple benefits for both planning and operation and maintenance.

Planning:

- Allows long-term simulations on the network to be carried out, enabling the design of network extensions for urban expansion or the replacement of aging infrastructure. 
- Can simulate emergency scenarios, allowing for better preparation.

- More efficient operating procedures and guidelines can be developed in an environment where there is zero risk involved.

Operation and Maintenance:

- Allows scheduling of maintenance activities on optimal days and at optimal times, so that the effected part of the network incurs the smallest possible disturbance.

- Can be used to identify anomalies in the system by comparing real-time data with simulated data.

The work of [33] builds on the idea of a 'package solution' and discusses how a complete DT can be a virtual replica of all processes, allowing monitoring from raw water catchment all the way to the consumer's tap. Concluding by praising the efforts of Global Omnium, GoAigua and the UPV in becoming one of the first utilities to implement a DT, and exposing great benefits that will become standard in advanced smart cities, the authors of [33] also comment that, for future development, there is a need for increased interconnectivity between models, with important elements such as a water quality model still to be developed for this project.

\subsubsection{Digital Twins in Energy Systems}

Significant economic losses can occur from the failure of pipeline assets. Service shutdowns can cause accidents and casualties, as well as affecting upstream and downstream systems [62]. Oil and gas operators are looking for improved operation maintenance strategies to reduce downtime from costly planned or unplanned maintenance. Extensive research and development activities are carried out to accurately predict the remaining fatigue life of pipeline assets, as well as maintenance requirements, based on data-driven digital models [63].

A conceptual DT has been proposed in the form of a data-driven digital replica of a subsea pipeline system where integrated sensors continuously update a finite element computational model [63]. The authors envision the twin being used to predict future conditions, study abnormal responses and estimate the remaining fatigue life of the asset. Other research has explored PetroChina's proposal to create a top-level intelligent pipeline network with a DT as the core [62]. Here, the twin is defined as a digital model which is precisely mapped from, and grows together with, the pipeline system as it is iteratively optimised. Both papers advocate the potential for predictive maintenance enabled by DTs. Traditionally, corrective maintenance is applied after the occurrence of an actual fault, which incurs costs. Planned maintenance is performed at scheduled time intervals, leading to unnecessary costs arising from unwarranted inspection or repair [63]. Having a maintenance cycle that is excessively planned can lead to over-maintenance. Furthermore, inability to observe the real-time status of equipment means that repairs cannot be performed as soon as there is failure [62]. A DT can be employed to compare model output data with measurement data from integrated sensors, in order to optimise maintenance scheduling. Using machine learning algorithms, the DT could predict a suitable maintenance strategy [63].

In a maintenance-based use case, a proposed DT-based system utilises the Russianmade robotic system, Cablewalker, and a DT to provide preventative maintenance for overhead transmission lines (OTL), which provide power to communities over long distances [34]. The DT aspect to this approach consists of a 3D model of the network of OTLs, containing all relevant data on the condition of all key components. The value of using the DT is that results obtained over a period of time can be compared to standard values, and the development of defects can be predicted before they occur. In practice, this system has been trialled on a $2.34 \mathrm{~km}$ section of OTL and 112 defects were detected, where previously only three were detected using manual inspection.

The potential application of DTs for intelligent management of thermal power plants has been explored, using one in Shadong province in China as an example [35]. The architecture for the reviewed DT consists of a physical layer, which includes elements such as 
monitoring equipment, pumps and valves, as well as a data layer, which includes operation parameters, water quantity/quality parameters, linking the physical to the digital world. The authors claim that thanks to the employed intelligent water resource management system, water intake was reduced by 800,000 tons per year. Other benefits include operational stability, consistency in quality and comprehensive allocation of resources arising from intelligent predictions.

A DT solution for fault diagnosis in photovoltaic systems shows the potential for easy maintenance and online fault remediation, where the DT can quickly identify a fault without adding significant complexity to the system. The DT architecture is transferrable and can be applied to other energy conversion systems [64].

\subsubsection{Digital Twins in Waste Management Systems}

Extensive research is being conducted to improve control strategies and process monitoring systems within the wastewater sector [65]. However, more progress has been made in water distribution systems, which rely mostly on well-established water quantity sensor data. Effective wastewater management, however, depends more on water quality sensors, which are notoriously unreliable, and the associated data are hard to collect. The authors of [65] advocate for the use of DTs to enhance water resource recovery facilities, alluding to adaptive plant models, predictive maintenance and plant-wide control for cost reductions, resource recovery and improved water quality.

In a digital transformation use case operated by a private group of utilities in Brazil and aiming to combine intelligent 3D models and DTs to improve the strategic decisions of treatment plants, the authors estimate that the life of critical system assets can be extended and millions of Brazilian Reais could be saved by switching from reactive to proactive maintenance. This will also significantly reduce the events of unpredictable equipment breakdowns [66].

Research in [67] proposes a design for a decision support system to complement a novel urban farming framework called aquaponics. This technique optimises logistics by shortening the distance between producers and consumers. However, this results in a complex human natural coupled production system which comprises interacting subsystems and several stakeholders. This complexity calls for data-driven solutions in the form of a DT, which can work towards improved communication between stakeholders and heterogeneous components such as the synchronisation of production units to respond to consumer demand in real time to minimise waste. Sensors can be implemented to monitor attributes such as water and room temperature, humidity, feeding events and $\mathrm{PH}$ levels. This system can be further enhanced with machine learning algorithms to optimise production and quality goals.

\subsubsection{Digital Twins in Telecommunication Systems}

A network of several DTs has been proposed to solve problems in complex telecommunication systems, with each twin serving as a model of one object, such as a switching node. The network of DTs will employ big data, data mining and neural networks to accumulate information and set up a good base for the development of telecommunication networks [68]. An important feature enabled by this network is traffic monitoring, which proves valuable during emergency situations where equipment tends to fail and traffic experiences avalanche-like growth. Additionally, the services requested by users during this time can change drastically. These complexities can be addressed by the network of twins, which can tackle urgent problems to do with the multiservice network during emergencies through its feedback loops. The authors discuss the ability of the network to carry out simulations to answer the: "What will happen?" question. However, they comment on the current inability of the system to effectively answer the: "Why can this happen?" question, which calls for future research and development.

Research has discussed how current 5G networks use expert knowledge and machine learning algorithms in the search for optimised decision-making [69]. However, these 
are unable to adapt to the dynamic changes of high-dimensional network states and can produce undesired results. Although reinforcement learning can address these issues, it is difficult to obtain data samples and it is risky and time consuming to simulate real networks. The authors of [69] propose combining these elements with DTs for the selfoptimisation of mobile networks. Their framework can predict the future network state based on optimisation decisions obtained by expert knowledge and reinforcement learning. This information can be fed into the DT to simulate different outcomes, which inform the final decision.

The Internet of vehicle sensors suffers from reliability concerns due to faulty equipment, weather concerns, and battery issues. This can result in incomplete datasets, which hinders the potential for smart scheduling and predictions. To address these challenges, a framework for a real-time traffic data prediction DT model, enabled through 5G, has been developed [70]. This framework was proposed due to the Internet of vehicle sensors not being fully reliable due to factors such as faulty equipment, weather or battery issues. Additional work has also touched on some limitations of conventional data-driven methods, discussing how they rely on the physical asset and its historical or online data with little connection to its virtual model [71]. If these data are insufficient or become compromised, the associated solutions lose effectiveness as false alarm rates increase and fault prediction becomes inaccurate. A DT model can offer prediction for these missing data through powerful 5G communication and time-aware, locality-sensitive hashing. A set of tests were conducted using a traffic dataset from Nanjing, China and results show the effectiveness of the proposed framework for short-term traffic condition forecasting [70] The authors recommend future development on failure prediction, energy cost and privacy preservation.

In fault diagnosis and health monitoring systems for satellites, conventional solutions collect large amounts of telemetry data and rely on operators to address anomalies. This framework can be error prone and struggles to adapt to the rapid growth of systems. To tackle this, models must develop deep integration with the virtual world to allow for realtime interaction with the physical asset. A DT fault diagnosis and health monitoring system has been developed that combines simulation data, telemetry data and fused data to realise the real-time monitoring and maintenance of satellites in orbit [71]. The DT can provide real-time visual monitoring without manual intervention by operators. Additionally, it can evolve as more knowledge and information is fed to the system, increasing the effectiveness of the model. The authors concluded that this solution can also be applicable to other satellite subsystems, and even whole satellite systems.

\subsection{Interview Findings}

The interviews raised some very important points surrounding DTs. These points were divided into themes and are reported below. Where references have been made to the opinions of a specific interviewee, their identification letter is been denoted in brackets, i.e., for interviewee A: (A).

\subsubsection{Definition of Digital Twins}

Most interviewees were supportive of the first part of the DT definition: that they are a realistic digital representation of physical assets, processes and systems. Interviewees made the distinction that DTs do not necessarily have to represent something 'physical' $(B, C)$, but that the subject simply has to be 'real' (B). The interviewees also all agree that DTs need to have some sort of bi-directional connection to the real twin (real twin meaning the real asset, process or system). However, there is some difference of opinion as to whether further requirements are needed to define something as a DT. Interviewee E believes that for something to qualify as a DT, it needs "to be capable of answering questions about that system" because "we've been doing large scale data descriptions of the world for donkey's years and digital twins are supposed to be something relatively new". Interviewee G indicates agreement, stating: "The only thing that seems to hold it 
[the DT concept] together is that it is a collection of data about something, useful for a purpose. The word we used to use for this is information, and as far as I can tell, Digital Twin is very nearly a synonym for information".

\subsubsection{Implementation of Digital Twins}

The topic of the implementation of DTs, which includes the mechanism as to how they operate, the technology used, and how DTs can be realised effectively, was found to be key to further refining the definition of DTs.

With regard to the refresh rate of data flowing into DTs from the real subject, interviewee $F$ thinks that there are some use cases where using real-time data would not be possible or even necessary. This is a view shared by interviewees A and B, who expressed that the refresh rate of incoming data does not define a twin and that this rate does not need to be real time, but right time.

On the requirement of machine intelligence in DTs, the majority of interviewees agreed that $\mathrm{AI}, \mathrm{ML}$, simulations and data analytics can all play a part in the implementation of certain DTs. However, they are not a defining characteristic of a DT, and instead these technologies should be included where they are required $(A, B, D, F)$. This idea is summed up by interviewee D: "intelligence does not necessarily have to have really high-tech software associated with it. It's around the best use of data for generating insights". Interviewee $\mathrm{C}$ does agree with this to an extent, insisting DTs should be purpose driven. However, interviewee $\mathrm{C}$ does not have much faith in ML and simulations, believing they focus too much on correlation rather than causality. Instead, and interviewee B agrees, DTs should focus more on assisting humans as opposed to replacing humans. Interviewee $\mathrm{C}$ continues in their anti-simulation stance by asserting that design and construction use cases, and simulations in general, cannot be within the scope of the DT definition, as they have no connection to anything physical. Instead, DTs are essentially asset management solutions.

Whilst on the topic of technology, as interviewee B describes, the confusion around DTs being referred to "grammatically as a proper noun, as if it's a product that you can buy off the shelf". Interviewee B states that "the view of myself and many, is that a twin is not a product or technology, it's actually a methodology and a way of working".

Moving slightly away from the definition of DTs, interviewee $C$ was keen to discuss the concept of "systemising processes" in the development of DTs. In order to be able to "automate and get real value out of what we do in the built environment", the process essentially comes down to "how can you review a decision system if you cannot actually articulate it". Interviewee $C$ describes how this process would work within the context of DTs:

(1) Identify the use cases people want to implement

(2) Identify the activities within those use cases

(3) Systemise the processes involved and develop a diagram

(4) Figure out what data are needed

(5) Figure out what parts are dependent on other parts of that process

Interviewee D states that they are "a bit reluctant to see them [DTs] as the panacea, I suppose, of engineering" due to the uncertainties surrounding their outputs, as a result of the maths and assumptions that go into formulating DTs. Therefore, they recommend that there should be greater recognition of the uncertainties in the outputs of DTs and "development of how you visualise the uncertainties".

\subsubsection{Applications of Digital Twins}

As described above, all interviewees agree that the fundamental application of DTs is to generate insights, where they are highly scalable and can be used in many different situations (A, D). As interviewee A says, "anywhere in the systems processes and asset lifecycle processes, wherever decisions are being made you can imagine a digital twin could be used to help make better decisions ... all of that kind of maps out to an n-dimensional matrix of possibilities". 
Both interviewees B and C agree that DT research should be more focused on tangible, real-world applications, using existing technologies, as this is where they see the greatest return on investment (ROI). Interviewee B argues that people should stop talking about "digital twin as this mythical unicorn that can answer all problems", as the technology does not exist for that. Instead, people should see DTs as "a journey, not a destination". Interviewee $\mathrm{C}$ maintains their opinion on simulations, stating that they think the data models are not currently there to put their trust in and, although they do see some value in that area, they see it as only $20-30 \%$ of what can be achieved through concentrating on the "really powerful stuff that we can look at now, that we can solve, actually tackle because it's real-world, it's tangible".

Interviewee B states that most use cases you see are in the operational state of an asset, and that this makes sense, because "if you look at the cost of an asset through its lifetime, design is a marginal cost, construction is a big cost, but the operational life of 20, $30,50,100$ years is where the bulk is, and any reduction in risk in that phase is desirable". Interviewee $\mathrm{B}$ continues the theme of DTs for risk reduction by stating that DTs can provide the most value when used in situations where "safety is of paramount concern. So, you often look at the regulated industries: nuclear, oil and gas, rail, for example, or where access to site is somehow a commodity".

One theme which was recurring, being mentioned by all but one of the interviewees (A, B, D, E, F), was the need to connect DTs. The reason for interconnecting DTs is that it provides a more realistic representation of the real world; the "real world is interconnected" (A). Another topic which comes up is modelling the interdependencies between not only the constituent parts of a system, but between different sectors (A, D, E, F).

\subsubsection{Data Usage and Security Concerns Surrounding Digital Twins}

There is consensus among interviewees that cybersecurity is an issue that needs to be dealt with regarding DTs. The reason for this, as mentioned by the majority of interviewees, is that the interconnectedness of DTs means a need for data sharing (A). Therefore, a conflict emerges between the need for available, shared data, and ensuring a level of security prevents this data from getting into the wrong hands, as there is high potential for terror threats in this space (A, B, C, D, E).

Interviewees suggested potential ideas for managing this balance. Both interviewees $\mathrm{A}$ and $\mathrm{E}$ mentioned research into using data trusts to manage data sharing. Whilst the majority of interviewees agree this is a complex issue, interviewee $C$ thinks that it should not pose much of a problem so long as DTs are implemented correctly. Interviewee C promotes the idea of thin twins, which are "single use-case specific datasets", as opposed to fat twins, which are a "multi-use case pile of data that is multifunctional". They believe this can solve the problem of data security as, if DTs are "thin" on data, "when you need to share that with someone, then they've only got access to that limited amount of data".

\subsubsection{Awareness and Education of Digital Twins within Industry}

All interviewees agree that there is very high awareness of DTs within the industry. As interviewee A states, "the market is measured in billions and we're only just at the beginning of it". However, there is also agreement that, while awareness may be high, there is a great lack of understanding as to what DTs actually are, with many citing the plethora of definitions in industry and lack of a consensus as reasons for this $(B, C, D$, $\mathrm{E}, \mathrm{F})$. Another culprit is software vendors selling into the market $(\mathrm{B}, \mathrm{C}, \mathrm{D}, \mathrm{E})$, who state they can sell you a DT as a black box of magic, without the consumer fully understanding what DTs are or what they can deliver (B). In addition, suppliers are "renaming everything they used to do to be a digital twin, which is then confusing the market and then it deincentivises innovation" (C). Interviewee B also states that DTs are a "methodology and way of working" as opposed to a "product or technology".

Some potential solutions to this issue were proposed by the interviewees. Interviewee $\mathrm{C}$ thinks formal standards can facilitate a shared understanding of DTs, as then the defi- 
nition of a DT is neutral and does not evolve from one research organisation, university or company, etc. However, they state this is not yet possible, as a consensus on what constitutes a DT has not yet been formed. Interviewee E thinks that the focus of industry should be on establishing a basic level of digital maturity across organisations and ensuring data are in more useful formats, before moving onto more complex digital ideas, because there is a risk of overselling the possibilities of DTs if this is not carried out.

\subsubsection{Government Contribution to Work on Digital Twins}

When asked about the UK Government's contribution, performance and level of support for the development of DTs, interviewees were generally complimentary, with some stating explicitly that the government is "providing fantastic leadership" (A), "worldleading ... some of the best stuff in the world" (B) and "we're at the forefront internationally of having leadership on this from the government" (D).

Multiple interviewees then described this support in terms of funding for various initiatives such as the CDBB organisation and National Digital Twin (NDT) programme (A, B, C, D, F).

On the issue of government investments, both interviewees $C$ and $D$ state that there are potentially too many separate investments, and that it would be beneficial to have a more centrally controlled view. However, interviewee D believes there are efforts underway to generate funding for a new programme "that would sit above all of those other investments, that would be specifically on digital twin", to remedy this problem.

\subsection{Survey Findings}

This section focuses on extensive comparisons between the core themes identified in the literature and in the responses to the survey. This was carried out to validate the relevance of current academic papers but also to identify anomalies and shed light on elements that require further research. The findings are structured by sector and broken down by themes that are featured in both the literature and the survey. The following themes were formulated and discussed for every sector:

- DTs of Real Systems: Discusses the development of DTs for physical assets or systems and processes.

- Human input: Addresses the role of human interaction in DTs and what the future offers.

- Regulation and Governance: Development of common standards, centralised against decentralised data storage and decision-making, and surrounding regulations.

- Data Challenges and Quality Control: Discusses the elements of data science that hinder or promote the development of DTs.

Waste management and telecommunication systems were grouped together since there were no survey results to evaluate against. Nevertheless, it was considered valuable to identify any themes that could correlate with other sectors for a more holistic understanding of DT development across all sectors.

\subsubsection{Overview}

Out of 30 survey respondents, $73 \%$ were involved in the creation of a DT, and only $23 \%$ were active users of DTs. Figure 2 shows the distribution of survey responses across infrastructure sectors, with smart cities the most common sector for DT activity among respondents. 


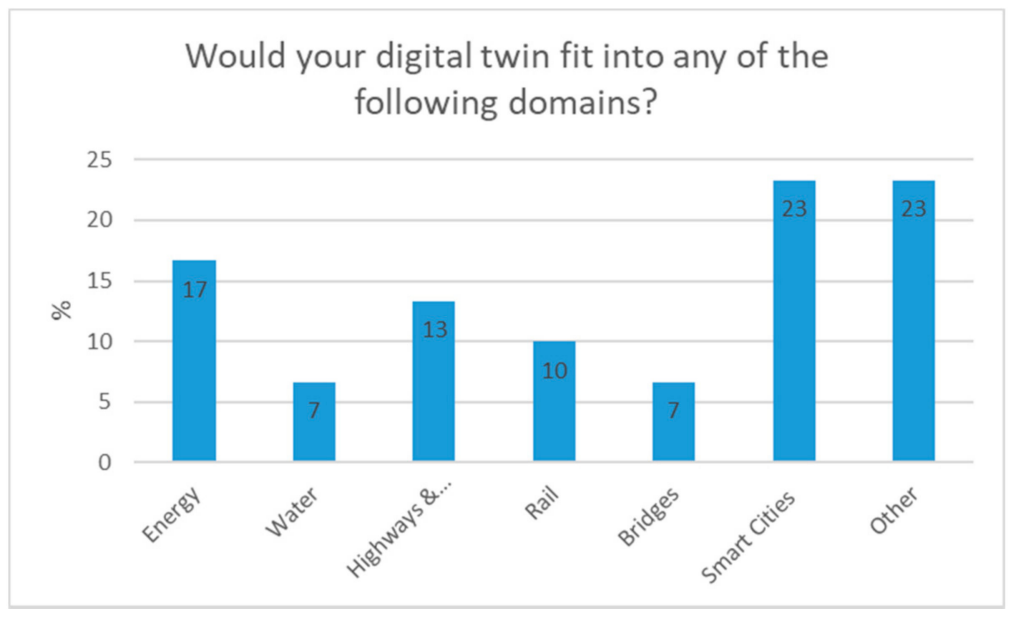

Figure 2. Sector distribution from survey results.

Other significant findings include an agreement rate of $80 \%$ among respondents that a bi-directional link between the subject and the twin must exist in a DT. One hundred per cent of respondents agreed that a DT must provide the ability to be queried to obtain information about the subject. Eighty-seven per cent agreed that a DT can model not only a physical asset, but also systems and processes as long as they are real. Seventy-three per cent believe DTs should have common standards and $70 \%$ believe that there is a lack of regulations. Finally, $80 \%$ think that ensuring data are protected and trust is maintained remains a major challenge for the development of DTs going forward. One survey question aimed to establish a consensus on the best definition to describe a twin. Fifty-three per cent of respondents agreed on the best definition, as illustrated in Figure 3.

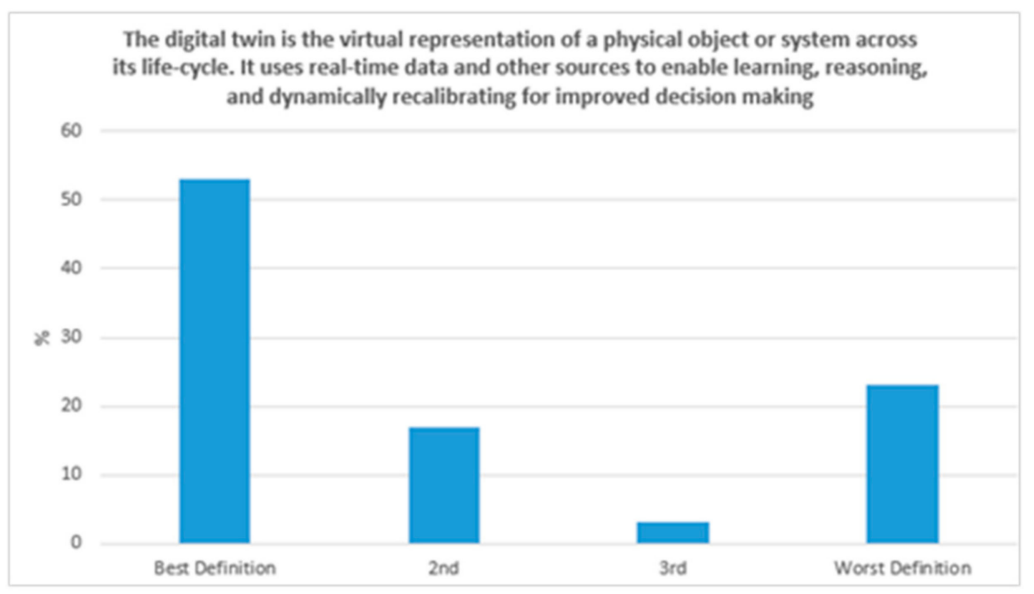

Figure 3. Most popular definition of a DT among survey respondents.

This paper aims to analyse DT technology development by infrastructure sectors. However, some survey respondents claimed that the DT they have worked with can belong to multiple sectors. This suggests the existence of a cross-sectoral perspective, which is explored further in the discussion section of this paper. Furthermore, not all the survey results were analysed, especially a question which asked respondents to rank existing DT definitions from one to four. These results remained inconclusive, as there was no definition that was ranked significantly higher than another. 


\subsubsection{Smart Cities}

\section{Digital Twins of Real Systems}

Respondents agreed that DTs should represent real systems and have the ability to deliver information in response to queries. The literature highlights this feature through a variety of use cases and conceptual proposals. For example, the DT presented in [50] is designed to be queried through a virtual reality framework, with the aim to minimise risk and lower associated costs by being able to estimate the effects of any implementations in advance. The work of [24] highlights how a DT has the potential to stimulate growth by providing a living testbed in which to test scenarios, ultimately allowing the twin to learn from the environment by analysing changes in data. Although smart cities are responsible for the collection of data, DTs employ these data to create information and forecast potential futures when decision makers need to evaluate potential future conditions [49]. The predictive capabilities of DTs rely on this real-time and historical data [51]. Analysts can query this data and simulate 'what if' scenarios to anticipate future behaviour.

\section{Human Input}

Respondents agreed that a DT can still be considered one when there is a human in the loop. The literature speaks about how a digital society can enable increased visibility into the interactions between humans and infrastructure [51]. Human input is needed at the social scale, with technology calling for citizen engagement in order to establish smarter cities. The same concept is featured in the work of [50], which encourages citizens to participate in virtual reality trials for the creation of smarter towns and cities.

\section{Regulation and Governance}

Respondents agreed that DTs should have common standards. This view is supported by [24], which highlights that a challenge for the development of DTs lies in developing a standardised approach to modelling from initial design to simulation stages. The authors argue that some sort of standardisation is needed to provide understanding between all parties and a comprehensive flow of information as the twin evolves. They conclude that a lack of standardisation in the modelling process and the absence of a widely accepted definition of a DT is slowing down progress. However, survey respondents disagreed that DTs should be centrally governed. This correlates with what the literature offers. For example, [50] touches on how big data models are often in the hands of large ICT companies and therefore create dependencies of municipalities, administrations, politics and society. This is especially evident in small- and medium-sized cities which outsource these projects to ICT companies due to a lack of resources. The vision of a smart city is one with increased transparency and involvement of citizens as part of a digital transformation. In the long term, a data monopoly and lack of civic participation can increase social inequality. Smart cities should strive to improve quality of life for their inhabitants, rather than focus on achieving growth or economic efficiency, as typically seen in the private sector. To realise this vision, a more holistic and comprehensive understanding of the complexities in urban systems, which considers economic, social and environmental issues, is needed, as conventional planning tools fail to provide this. The DT presented in [50] allows for visualisation of complex processes through virtual reality, where the citizens of Herrenberg, Germany can be involved in planning. This open-access data framework aims to give back sovereignty of data and access to information to all citizens. The authors believe this is crucial in building future democratic cities, stressing that they do not want to create the type of commercial product commonly seen when providers such as Google, Cisco and IBM provide urban data and smart city solutions. The authors of [50] acknowledge that complex data can be difficult to understand for an average citizen. However, the virtual reality platform is designed to facilitate communication with the aim of involving a diverse group of citizens in order to develop consensus. To improve this process, a survey was conducted on the comprehensiveness of the VR system, with the end goal of democratizing urban data and preserve the sovereignty of data and smaller communities. 


\section{Data Challenges and Quality Control}

Researchers have paid special attention to data protection whilst installing sensors in urban areas [50]. The privacy and security of DTs are challenging because there is a large amount of data involved, some of which may be sensitive. Overcoming this challenge begins with ensuring enabling technologies, such as data analytics and IoT, adhere to practices and updates in security and privacy regulations. While this will build trust in DT technology, further efforts have to be made to inform organisations about the benefits of DTs. Additionally, verification that the technology is performing as expected and promised is essential for building trust. Regulation is a way to ensure the protection of personal data, as is the use of a decentralised training model platform which excludes data sharing when employing data analytics [24].

With IoT technology increasing in adoption, the challenge consists of monitoring the flow of large amounts of data, organizing and using it effectively. The greater the number of interconnected sensors and devices, the greater the amount of unstructured data. Negligence in controlling data flow can result in mismanaged or lost data, which can be utilised in cyberattacks. For example, the Mirai botnet scandal involved 15 million IoT devices being compromised [24].

Smart city DT systems are still in their infancy. This comes with development challenges at the community level, such as digital communication systems not accurately reflecting community processes, as well as a lack of data security and privacy issues [49] Data quality is hugely important, and data should be organised and cleaned to ensure only high-quality data are used in DTs. Additionally, data from IoT devices and other sensors have to be collected through an uninterrupted, noise-free data stream, as inconsistent data jeopardises a DT's ability to be effective [24].

\subsubsection{Energy \\ Digital Twins of Real Systems}

Respondents agreed that a DT must provide the ability to be queried for information. The selected literature features use cases where DTs are used for decision support. For example, the DT supporting thermal power plants presented in [35] is able to be queried with the aim of running diagnostics and optimisation, intelligent predictions and intelligent decisions. Similarly, the DT to support the management of oil and gas pipeline systems presented in [62] can provide comprehensive prediction, integrated management and control and process optimisation.

The survey shows that there is a general disagreement with the idea that a future/predictive/scenario model is not a DT. The literature correlates with this, as the above papers express the potential for DTs to simulate critical situations as part of the process of informed decision making.

\section{Human Input}

Respondents agreed that a DT is still a DT if there is a human in the loop. The literature shows evidence of this in cases where the twin acts as a tool for decision support. For example, a DT within an oil and gas pipeline system can evaluate data quality, energy efficiency, operation conditions and health status, ultimately allowing an operator to observe the real-time condition as well as future tendencies of the equipment in question. This allows stakeholders to execute informed decisions [62]. On the other hand, the DT presented in [63] features an ML algorithm to predict maintenance solutions based on discrepancies between model data and in situ sensory data, as well as estimating the remaining fatigue life of the subsea pipeline. This is made possible due to the low cost of modern sensory technology and advancements in artificial intelligence. This concept can also be observed in [64], where the DT in question acts as a control system which can quickly detect and precisely identify a variety of faults within photovoltaic systems. 


\section{Regulation and Governance}

Survey results show that it is considered important that DTs have common standards. The selected literature for energy does not exhibit substantial discussion on the matter except for a statement by [62], which mentions how data standards have not yet been unified, making it difficult to realise the data interaction between different systems.

\section{Data Challenges and Quality Control}

Respondents agree that data security, in the form of data protection and trust, is important for DT development. However, the literature does not offer much on this theme except for a comment by [63], which states that data analytics for a subsea pipeline system require robustness, reliability and security.

The majority of respondents believe that ensuring data used in DTs are of sufficient quality, accurate and use appropriate standards, is only a minor challenge. The literature contrasts this, with [62] stating that there are delays in collecting data during the construction and operation period. These data can be inaccurate and insufficient for effective analysis. There is also a lack of data on the external environment, as these are difficult to collect. The authors of [62] elaborate on the significant challenges, describing how DTs in the oil and gas sector are in their infancy, with significant improvements to be made in data collection, analysis and software development. They conclude by stating this technology has a long way to go before it is widely adopted and promoted within the industry.

\subsubsection{Transport \\ Digital Twins of Real Systems}

Respondents from the transport sector agreed that DTs should represent real systems with the ability to deliver information when being queried. For example, a DT could be queried to provide information on geometric deformities in a 3D representation of a bridge [58]. The work of [54] builds on the potential for simulations and argues that key to enabling DTs is using mathematical modelling to analyse the transport network and develop proposals for optimizing the network, to justify investments in transport infrastructure. Interestingly, survey respondents specifically from the highways and autonomous vehicle sector all agreed with the statement that 'A digital twin must have some form of computational or machine intelligence to generate insights based on incoming information, as opposed to just the human generation of insights'. Respondents also agreed that DTs do not always have to model a physical asset; they can also model systems and processes, so long as the object is real. This correlates with the work of [72], which proposes a DT of an Advanced Driver Assistance System (ADAS) and the work of [57], which discusses a DT model of an airport's traffic control system.

\section{Human Input}

Survey results suggest that a DT can still be classified as one even if there is a human in the loop. This correlates with most of the literature, which features DT applications in industry where typically a human utilises a DT for decision support. However, some papers discuss the future development of DTs, AI, and ML algorithms. For example, [57] touches on the evolution of a twin where, in its early stages, the role of a control system can be executed by a skilled operator. In the long run, user decisions can be stored in the twin's memory and called upon later to train a control system through a ML algorithm. The authors describe the DTs as virtual dynamic environments for learning agents, allowing for simulated environments which mitigate the risk of injury, property damage and regulation breaches that can arise from real-world experiments. The authors of [42] also believe future analytics platforms will consist of learning algorithms for the purpose of self-learning, training, reasoning and articulation of new evidence-based hypotheses.

Although damage recognition in bridges typically involves the presence of an expert, through digitalising the inspection process, ML algorithms can work towards automatic damage inspection [45]. 
Regulation and Governance

Respondents agreed that DTs should have common standards. This correlates with statements from [56], which advocate for the development of standards that determine the probability of failure-free operations and discuss how DT models can be useful for ensuring air traffic safety compliance. Furthermore, [45] touches on how smart bridge maintenance needs well-defined DT models.

In regard to governance, respondents do not believe DTs should be centrally governed. The selected literature for transportation systems does not yield much on this topic. However, [42] discusses centralised data lakes and their function in the creation of insightdriven transport management systems. The work of [45] makes a point on data security, describing a data lake as an open data platform held by the government. Although these papers highlight the benefits of having a centralised storage of data, there is no mention of centralised decision making.

\section{Data Challenges and Quality Control}

Respondents agreed that the major challenges surrounding DTs are ensuring that data is protected and trust is maintained, and ensuring that the data used in twins are of sufficient quality, are accurate, and use appropriate standards. The selected literature correlates with these answers. For example, [45] describes how regulation on data security is a significant obstacle to overcome for transportation systems. The authors add that DTs need collaborative knowledge from all parties, which is one of the most difficult challenges in the process of model definition.

The main challenges facing the development of DTs are further detailed in [73]. Firstly, there is a lack of standardised semantics. Secondly, it is difficult to incorporate a large number of small sensors. Additionally, it is difficult to deal with these sensors' high frequency of data acquisition. If these challenges are not addressed, the data amalgamation in DT could be compromised. Furthermore, data processing and conveyance presents a new set of challenges where the correct information has to be delivered comprehensively to end users.

Different DT applications call for different refresh rates in terms of how often the twin receives data. For example, the DT presented in [57] receives data on vehicle coordinates up to 10 times per second. The authors argue that this level of accuracy is sufficient for an airport traffic control system. Similarly, the DT presented in [42] supports a smart vehicle traffic system which has to act instantaneously to mitigate any risk of accidents. Therefore, real-time reactions where data are processed and insight is delivered is essential. On the other hand, a DT supporting the operation and maintenance of bridges would not need the same refresh rate as this would be inefficient given that bridge deterioration takes several years.

\subsubsection{Water}

Digital Twins of Real Systems

Respondents agree that a DT should be able to be queried to obtain information. The literature on DTs within water systems yields papers that discuss the concept of DTs as well as real use cases in operation today. A DT can be queried to detect and diagnose issues with equipment for the purpose of preventative maintenance [60]. In another example, DTs can be utilised for failure analysis of a treatment facility, enabling operators to become comfortable with critical situations through simulations of extreme conditions [61]. Through this simulation of dynamic processes, the twin can provide information on unforeseen shortfalls or realisation of additional unplanned capacity. This harmonises with the opinion of respondents that DTs do not always have to model physical assets but can also model systems and processes. In the use case of a DT of a water distribution system in Valencia, Spain, the twin can be queried for planning strategies such as simulation of long-term network behaviour and the design of replacement plans and operation protocols. Additionally, the twin can provide information on operation strategies 
such as decision support, maintenance schedules, operator training and building deep network knowledge [33].

Respondents disagreed with the notion that a future/predictive/scenario model is not a DT. This contrasts the opinion of [60], which states that a simulation model or a supervisory control and data acquisition (SCADA) system are not DTs in and of themselves.

\section{Human Input}

Respondents believe that a DT remains one even when a human is in the loop. This statement can be observed in the literature, with [60,61], and [33] highlighting the benefits of a twin as a decision support tool. Nevertheless, [61] expands on the potential for ML and data analytics to enable the twin to engage in automated data quality control to ensure clean and accurate data streams are uploaded for simulations. Additionally, [74] refers to the complete DT of a water distribution system as one which is involved from raw water collection to the tap of the end users. Throughout this water cycle, the twin can optimise decisions, mitigate risks and identify anomalies to ensure the physical and cyber security of the asset.

\section{Regulation and Governance}

Respondents believed that developing a consensus definition for DTs is only a minor challenge. However, [33] states that a precise definition has not been developed for a DT of a water distribution system and that becomes an obstacle when differentiating this technology from other similar applications. Establishing open standards for data as well as standard API solutions will improve the DT system architecture and is essential for future DT development [60].

\section{Data Challenges and Quality Control}

Respondents believe that a major challenge in the development of DTs is securing continued access to data from third parties, including consumers. This theme can be viewed from a risk management perspective; for a DT to live up to expectations, close interactions with end users should be undertaken throughout the lifecycle of the twin [60]. Additionally, maintaining transparency through open standards will lower the barrier to entry for developers and investors, ultimately fuelling innovation and securing trust between parties.

Survey results show that ensuring DTs have up-to-date data is considered a minor challenge. Though [33] does not directly address the complexity of this task, a use case is presented which exhibits a significant degree of control over the refresh rate of the DT. For example, the main data sources feeding DTs of water distribution systems are geographical information systems and supervisory control and acquisition systems. The former can be updated once a week, while the latter should be updated every $5 \mathrm{~min}$. The DT used in Valencia, Spain, is updated every minute. From this information, it can be concluded that feeding a DT up to date data is a minor challenge within the water industry. However, this could be more difficult for a more demanding sector, such as autonomous vehicles, which could need several updates per second.

\subsubsection{Waste Management and Telecommunication Systems Digital Twins of Real Systems}

The selected literature on waste management systems and telecommunication systems features conceptual as well as real use case DT solutions. Research in $[65,68,69,75]$ propose the implementation of DTs to simulate processes for an array of benefits. These proposals harmonise with the general agreement within the survey that a DT can simulate systems and processes, not only a physical asset. Furthermore, [66,67] present real use cases that act as decision support tools for the existing infrastructure. 


\section{Human Input}

A general consensus observed in the survey was that a DT remained a DT regardless of a human in the loop. Most of the literature in the waste management and telecommunication sectors considered a DT a useful decision support tool. Some of the literature explored further evolution of the technology. For example, the DT presented in [71] could offer real-time monitoring of satellites in orbit without manual intervention by operators, while [69] outlines how introducing ML algorithms to DTs can achieve self-optimisation in mobile networks. Finally, [67] discusses how an already successful DT support system can be enhanced with ML algorithms to optimise production and quality goals. These papers seem to agree that ultimately replacing a human in the loop with intelligent algorithms will render the DTs more efficient.

Regulation and Governance

The selected literature on these sectors did not offer significant discussion around this theme.

\section{Data Challenges and Quality Control}

In the history of data-driven models, criticism has focussed on a lack of transparency, which results in a lack of trust. These models also face the challenge of following best practice when there is not a general consensus on standards, practices and quality control [65]. This correlates with previous discussions and survey results which advocate for transparency, clear communication and open standards. The authors of [65] also touch on mismanaged data and describe how uncontrolled development and a lack of expertise can result in data graveyards which consist of large amounts of unused data. For a successful system architecture, collaboration of data governance experts is essential.

Finally, the issue of quality in data acquisition has been considered, recognising that sensors can suffer from a range of faults which can result in incomplete data, and therefore limit the effectiveness of future data analyses [70].

\subsubsection{Future Work}

Significant findings from survey results were compiled into Figure 4 . The purpose of this was to identify anomalies and elements that require further research, which are highlighted in red.

Generally, the survey results correlated well with literature except within the regulation and governance theme. The only sector that had featured strong correlation for this theme is smart cities, where there is extensive evidence of developers advocating for decentralised governance and an active inclusion of the general public as part of development.

It would be useful to evaluate additional opinions of experts working in the water sector to determine if the highlighted anomaly remains true, as only $7 \%$ of survey respondents were involved with a DT in the water sector. In contrast, a lot of quality literature and use cases from the water sector were retrieved from the Scopus database. Similarly, additional experts within the energy sector can be queried about the challenges of ensuring trust and data quality for DT projects, to explore the anomaly in this theme.

The waste management and telecommunications systems sector are highlighted in grey because the Figure 4 is set up to evaluate survey results against literature. Nevertheless, the summarised findings of these sectors lend credibility to the conclusion that regulation and governance, where there are gaps in knowledge and a lack of consensus, is an important theme for future research. 


\begin{tabular}{|c|c|c|c|c|}
\hline & $\begin{array}{c}\text { Digital Twins of Real } \\
\text { Systems }\end{array}$ & Human Input & $\begin{array}{l}\text { Regulation and } \\
\text { Governance }\end{array}$ & $\begin{array}{c}\text { Data Challenges and } \\
\text { Quality Control }\end{array}$ \\
\hline Smart Cities & $\begin{array}{l}\text { Lite rature \& survey } \\
\text { agree that DTs can be } \\
\text { predictive models of } \\
\text { real processes and } \\
\text { systems }\end{array}$ & $\begin{array}{c}\text { Strong are ement in } \\
\text { lite rature \& survey on } \\
\text { human input. Strong } \\
\text { emphasis on Smart City } \\
\text { development }\end{array}$ & $\begin{array}{c}\text { Strong areement in } \\
\text { lite rature \& survey on } \\
\text { decentral ised } \\
\text { preference }\end{array}$ & $\begin{array}{l}\text { Strong agreement in } \\
\text { lite rature and survey } \\
\text { on major challenges } \\
\text { being data security, } \\
\text { privacy and quality }\end{array}$ \\
\hline Energy & $\begin{array}{l}\text { Literature \& survey } \\
\text { agree that DTs can be } \\
\text { predictive models }\end{array}$ & $\begin{array}{l}\text { Lite rature \& survey } \\
\text { agree that humans can } \\
\text { be part of the loop. } \\
\text { Literature explores } \\
\text { automation. }\end{array}$ & $\begin{array}{l}\text { Common standards } \\
\text { for DTs considered } \\
\text { important in survey } \\
\text { but not in literature }\end{array}$ & $\begin{array}{l}\text { Trust and quality of } \\
\text { data assumed to be } \\
\text { easy in survey but } \\
\text { not in literature }\end{array}$ \\
\hline Transport & $\begin{array}{l}\text { Literature \& survey } \\
\text { agree that DTs must } \\
\text { have computational } \\
\text { intelligence }\end{array}$ & $\begin{array}{c}\text { Literature \& survey } \\
\text { agree that humans can } \\
\text { be part of the loop. } \\
\text { Lite rature explores } \\
\text { automation. }\end{array}$ & $\begin{array}{c}\text { Centralised } \\
\text { governance prefered } \\
\text { in literature but not in } \\
\text { survey }\end{array}$ & $\begin{array}{l}\text { Trust and quality of } \\
\text { data is important in } \\
\text { survey and literature }\end{array}$ \\
\hline Water & $\begin{array}{l}\text { Predictive model is } \\
\text { considered a DT by } \\
\text { survey and not by } \\
\text { literature }\end{array}$ & $\begin{array}{l}\text { Lite rature \& survey } \\
\text { agree that humans can } \\
\text { be part of the loop. } \\
\text { Lite rature explores } \\
\text { automation. }\end{array}$ & $\begin{array}{l}\text { Developing a } \\
\text { consensus definition } \\
\text { considered easy in } \\
\text { survey but not in } \\
\text { literature }\end{array}$ & $\begin{array}{l}\text { Securing continued } \\
\text { access to data by all } \\
\text { parties considered } \\
\text { important in both }\end{array}$ \\
\hline $\begin{array}{l}\text { Waste } \\
\text { Management } \\
\text { \& Telecom }\end{array}$ & $\begin{array}{c}\text { Literature agrees that } \\
\text { DTs can be predictive } \\
\text { models }\end{array}$ & $\begin{array}{c}\text { Literature agrees that } \\
\text { humans can be part of } \\
\text { the loop and explores } \\
\text { automation. }\end{array}$ & Incond usive & $\begin{array}{c}\text { Trust and quality of } \\
\text { data important in } \\
\text { literature }\end{array}$ \\
\hline
\end{tabular}

Figure 4. Summary of Sectors vs. Themes.

\section{Discussion}

\subsection{Characteristics of Digital Twins}

The survey results highlight inconclusiveness in regard to a formal DT definition, which harmonises with what most of the literature discusses: there is not a general consensus established regarding a comprehensive definition for DTs. The definition given by [76] presents a clearer distinction between less advanced models and digital shadows, and a DT with a higher fidelity. However, it is possible that by introducing another term in 'digital shadow' (as the term digital model currently exists), there is a risk of further muddying the waters.

A better way of looking at the issue is to establish a standard threshold at which something can be defined as a DT and then progress from this in levels of increasing fidelity (or complexity). The reason the word fidelity is chosen rather than hierarchy or maturity is because those words emphasise the incorrect notion that all DTs must be incredibly complex automated systems to have value, and that this is the target for any implementation of a DT, which is simply not the case for many applications.

It is also pertinent to note that the ability to create what [76] defines as a DT, "automated control of the physical twin", is currently quite rare, if possible at all, in the vast majority of applications. DTs should be purpose-driven, so may not require this level of complexity. As long as data from the physical twin are inputted into the DT and some sort of control mechanism exists to implement the derived insights—a feedback loop which could include the use of humans-it would still be considered within the scope of a DT. The data refresh rate of this feedback loop, or bi-directional connection, does not matter, but the system must have some sort of intelligence and way to derive insights. Otherwise, it is just a collection of information such as in BIM or a register like the National Underground Asset Register (NUAR) [77] which, although extremely useful, are concepts which have existed for years. 
Although the Gemini Principles' definition has been influential in stating the need for a connection between the physical and digital, it does not go far enough to distinguish a DT from a generic model, or most digitally held pieces of asset information for that matter. This is evidenced by the fact that literature, survey respondents and all interviewees agree on the lack of a consensus within the industry, even though the Gemini Principles paper was introduced in 2018 [78]. There is, however, a consensus on the need for DTs to be purpose driven. The key requirement that would set apart planning or simulation models from a $2 \mathrm{D}$ or 3D model is the fact that these can provide a computational analysis of the information inputted into the DT and an output of insights by utilising machine intelligence. Two- or three-dimensional models cannot do this, as a human is required to derive the entirety of the insight. This does not mean that human in the loop is not within the scope of DTs, it is just that within the generation of insights there must be at least some involvement of computational analysis, whether that is in the form of ML algorithms, data analytics or simulation, as otherwise the main benefit of having the DT would be that the information is visualised digitally.

Taking the definition from the Gemini Principles as a qualifier, a DT is of course quite vague and could certainly be a synonym for all asset information which is held and visualised digitally, which would not be a very significant or worthwhile departure at all.

When considering what "assets, processes and systems" DTs can apply to, the Gemini Principles does not provide an answer. However, as both interviewees B and C state, DTs can apply to things which are "real" and there is no need for something to be "physical", as there are things within the scope of DTs are not physical or do not have a geometry attached. DTs do require the real twin to exist. Existing DTs can also help to inform new designs by looking at lessons learned, but there cannot be a DT of the design itself, as this is just a simulation or model, and not based on something real.

Another important issue, raised by interviewee B and supported by survey findings, is that DTs are a "methodology and way of working" as opposed to a "product or technology". DTs can be implemented in various ways and for different applications, as shown in this paper. However, they all share the same common baseline features that define them as DTs.

As demonstrated throughout this discussion, the importance of a sufficiently detailed definition cannot be understated. Therefore, an updated definition of a DT is proposed, based on that from the Gemini Principles, but further refined to state the need for a DT to refer to existing and real objects, that it is a process and methodology as opposed to a product, has a bi-directional connection, uses computational analysis of data to generate insights, and that DTs need to be purpose driven:

"A realistic digital representation of existing assets, processes or systems in the built or natural environment, which is not a product, but an on-going process which continuously refines this representation. A digital twin has a bi-directional connection to the real asset, process or system and contains a way of computationally analysing incoming information to generate valuable insights, for the purpose of one or more specific use-cases."

\subsection{Barriers to Implementation of Digital Twins}

An issue which can potentially inhibit the uptake of DTs is the level of trust that people have in the outputs given. This does not mean to say that DTs must be completely accurate and that errors cannot exist, as these can also provide learning opportunities. Instead, what gives people trust in a system is that they know they are not being misled and, as interviewee D rightly points out, this comes down to the importance of quantifying and visualising uncertainties when outputs are given. This is such an important aspect of implementing DTs, it is quite worrying not to see it mentioned more often in the literature, as there seems to be only one use case identified by this paper which covers this idea [44].

Interviewees and survey respondents agree that cybersecurity is an extremely important and complex issue in the context of DTs, and even more so with interconnected DTs. A consequence of open data sharing is the potential for terror threats, a concern amplified by the vital role CISs play in the normal operation of society. In one example, an 
attack on Pakistan's power network in 2015 left approximately $80 \%$ of the country without electricity [79].

A potential solution for this was brought up by both interviewees $\mathrm{A}$ and $\mathrm{E}$ on the use of data trusts to manage secure data sharing between DTs. This is a concept which originated from the Open Data Institute (ODI) to replace the current model for data sharing. Individual organisations can collect and store data, then make decisions about who can have access to this data, how they can use it and who receives the benefits derived from it. This could help with concentrating expertise surrounding data use within data trusts, as opposed to relying on individual organisations to have a high proficiency. This is also somewhat similar to elements of the CDBB's integration architecture model, demonstrated as part of their Information Management Framework (IMF) [80].

Standards for interoperability and a common database schema are key to moving DTs forward. The CDBB's IMF paper also lists both of these as core requirements in the formation of an IMF, which sets out standards and data exchange protocols to allow the secure implementation of connected DTs. For both of these requirements, they suggest a Foundation Data Model (FDM) and Reference Data Library (RDL) be at the heart of this, where the FDM will define a "clear ontology for the digital twin ecosystem" to set out descriptions of general concepts regarding DTs. The RDL will contain a more specific vocabulary, which is key to ensuring that everyone is using the same terms to describe the same things, and that there is a term for everything which exists in this system [80,81]. Both of these are good starting points for creating consistency across the development of standards and common database schema. A standard which comes from a neutral and immutable source would be the ideal way to educate the industry on DTs. However, a consensus definition needs to appear first to avoid further fracturing of ideas.

\subsection{Theoretical Implications}

While digitalisation has the potential to drive convergence, research into the applications of DTs has typically been siloed by sector. This is despite the fact that characteristics of DTs are in essence very similar throughout different sectors, and thus DTs demonstrate the capacity for cross-sectoral use. The main reason for this may be that most DTs to date have been use-case specific. However, this focus on application does not prevent DTs from being developed with basic architecture principles in common, allowing them to be integrated with other DTs. It is establishing this common architecture that presents the main barriers to DT implementation: dealing with uncertainties, cybersecurity, data sharing, and standardisation of data schema. To enable DTs to accelerate convergence, these barriers must be addressed earlier from an interdisciplinary perspective. These investigations should lead to co-evolution of theories of digitalisation to embrace the growing diversity of DTs.

\subsection{The Future of Digital Twins within Industry}

The results demonstrate a high level of awareness of DTs within industry and academia, shown by the current and projected market value and the number of papers published on the topic recently., However, there is a lack of understanding as to what DTs actually are, compounded by the absence of any consensus regarding a definition. This may be because the concept is still very nascent and the debate over what constitutes a DT is still ongoing, but also, as mentioned previously, the currently proposed definitions are generally too vague.

Another reason for this lack of understanding is the activity of software vendors and their efforts to market products and services which are not DTs, reducing the DT concept to a mere technology or product. Whilst this is damaging and does confuse the market, it is just a symptom of the problem, an opportunity to take advantage of a broken market. The cause is the popularity of the concept outpacing its actual development, which at its foundation requires consensus around a definition, a process which takes time, discussion and nuance. This overselling of DTs is not inevitable, and the potential of DTs can be 
capitalised upon by increasing the baseline of digital maturity required at each level of an organisation.

There is a need for management and digital leaders within organisations to educate themselves and their workforce on best practice regarding the implementation of innovative technologies such as DTs. As mentioned previously, increasing digital maturity such as the growing use of digital tools and the automation of simple and monotonous tasks can go a long way, but it does not stop there. This includes hiring the correct resources such as: solution architects, software developers, business analysts and domain specific subject matter experts. This stops DTs being implemented from a purely technological perspective and are instead delivered together with those with a knowledge of the issues that asset owners are facing, to ensure the scope of the DT is correctly defined and is use-case specific. In addition, those in industry with a well-developed knowledge of DTs can assist in overcoming the initial barriers to the adoption of DTs, as they are in a very strong position to educate and influence asset owners to consider the benefits of implementing DTs.

Largely through the work that the CDBB is conducting, the UK government is trying both to provide a central vision for the implementation of DTs and to drive a consensus by funding projects, such as the DT Hub, which aim to foster collaboration between those involved in developing DTs [82]. However, with so many investments into DTs within the UK, cohesion could be lost. Efforts to create a new organisation which would oversee all DT related projects could be crucial in tying together research findings and encouraging the collaboration needed to achieve a more unified approach.

Ultimately, it will be interesting to see how the government supports DTs going forward, and whether they are embraced as a technology that can support the target of net-zero by 2050 [83].

\section{Conclusions and Recommendations}

DTs are still in the very early stages of development. However, this is not the time for complacency, as it is crucially important to establish the foundations of this concept correctly, to facilitate the successful and widespread implementation of DTs for the benefit of all of society.

This paper has characterised the DT concept and explored the effectiveness of DTs within the context of CISs. This was achieved through the combination of a literature search, a survey of DT professionals, and a set of interviews with stakeholders.

The literature, survey, and interview findings have demonstrated just how much work there is to be done by academia, industry and also the state if DTs are to achieve their full potential. Therefore, the following recommendations are made:

1. The CDBB, as the main organisation involved in the development of DTs in the UK, should reconsider their definition of a DT, with the definition proposed in this paper being shared with the wider community for further discussion to validate/modify it.

2. There should be collaborative development of a structure of how to implement DTs more effectively, with an emphasis on systemising processes and being purpose driven. This allows better understanding of the real twin and therefore an awareness of the correct level of fidelity required of the DT.

3. Research should consider the quantification of uncertainties for DTs and promote better awareness within the industry of the need to visualise such uncertainties within the outputs from DTs.

4. Research into, and implementation of, DTs should concentrate on those with a shorter temporal scale to increase certainty. This is in addition to focusing on high value use cases where safety risks or access limitations are involved.

5. There is a need for research into how DTs can be retrofitted into existing infrastructure to improve efficiency and therefore reduce operational energy usage.

6. Further research is required into potential ideas for a framework to allow accessible yet still highly secure data sharing between interconnected DTs. 
7. Organisations should be encouraged to enact programs which increase the digital maturity of their entire workforce before embarking on more complex challenges such as the implementation of DTs.

8. An organisation should be created to oversee all government-funded projects related to DTs. This will allow for a more collaborative and unified approach which can both attract more government investment and create a central vision which serves to benefit all of society and not corporate interests.

Author Contributions: Methodology, L.V. and L.M.; data collection and curation, M.C. and L.M.; validation, all; investigation and conceptualization, M.C. and J.-P.C.A.; writing-original draft preparation, M.C. and J.-P.C.A.; writing-review and editing, L.M. and L.V.; supervision, L.V. All authors have read and agreed to the published version of the manuscript.

Funding: This research received no external funding.

Institutional Review Board Statement: All subjects gave their informed consent for inclusion before they participated in the study. The study was conducted in accordance with the Declaration of Helsinki, and the protocol was approved by the Ethics Committee of University College London (18765/001 Digital Twin Implementation and Utilisation within Infrastructure Systems).

Informed Consent Statement: Informed consent was obtained from all subjects involved in the study.

Data Availability Statement: The data presented in this study are available on request from the corresponding author. The data are not publicly available to protect the privacy of interviewees.

Acknowledgments: L. Varga kindly acknowledges EPSRC grant EP/R017727/1 relating to UK Collaboratorium for Research on Infrastructure and Cities (UKCRIC).

Conflicts of Interest: The authors declare no conflict of interest.

\section{References}

1. Burgess, G.; Enzer, M.; Schooling, J. Flourishing Systems; Centre for Digital Built Britain and Centre for Smart Infrastructure \& Construction, Cambridge: Cambridge, UK, 2020. [CrossRef]

2. Reed, D.A.; Asce, M.; Zabinsky, Z.B.; Boyle, L.N. A framework for optimizing civil infrastructure resiliency. In Proceedings of the Structures Congress 2011, Las Vegas, NV, USA, 14-16 April 2011; pp. 2104-2112. [CrossRef]

3. Oughton, E.J.; Usher, W.; Tyler, P.; Hall, J.W. Infrastructure as a Complex Adaptive System. Complexity 2018, 2018, 11-14. [CrossRef]

4. Gay, L.F.; Sinha, S.K. Resilience of civil infrastructure systems: Literature review for improved asset management. Int. J. Crit. Infrastruct. 2013, 9, 330-350. [CrossRef]

5. Bocchini, P.; Frangopol, D.M.; Ummenhofer, T.; Zinke, T. Resilience and Sustainability of Civil Infrastructure: Toward a Unified Approach. J. Infrastruct. Syst. 2014, 20, 04014004. [CrossRef]

6. UKGBC. Climate Change; UK Green Building Council: London, UK, 2020; Available online: https://www.ukgbc.org/climatechange/ (accessed on 14 September 2020).

7. IPCC. IPCC Global Warming of $1.5^{\circ} \mathrm{C}$ Summary for Policymakers. In Climate Change 2013-The Physical Science Basis; Cambridge University Press: Cambridge, UK, 2018. [CrossRef]

8. MarketsandMarkets. Digital Twin Market by Source, Type, Application \& Geography. 2020. Available online: https://www. marketsandmarkets.com/Market-Reports/digital-twin-market-225269522.html (accessed on 31 July 2020).

9. Petty, C. Prepare for the Impact of Digital Twins-Smarter with Gartner. 2017. Available online: https://www.gartner.com/ smarterwithgartner/prepare-for-the-impact-of-digital-twins (accessed on 25 July 2020).

10. Vishnu, S.; Ramson, S.; Senith, S.; Anagnostopoulos, T.; Abu-Mahfouz, A.; Fan, X.; Srinivasan, S.; Kirubaraj, A. IoT-Enabled Solid Waste Management in Smart Cities. Smart Cities 2021, 4, 53. [CrossRef]

11. Zanella, A.; Bui, N.; Castellani, A.; Vangelista, L.; Zorzi, M. Internet of Things for Smart Cities. IEEE Internet Things J. 2014, 1, 22-32. [CrossRef]

12. Finger, M.; Montero, J. Digitalization, efficiency and convergence. In A Modern Guide to the Digitalization of Infrastructure; Edward Elgar Publishing: Cheltenham, UK, 2021. Available online: https://www.elgaronline.com/view/edcoll/9781839106040/978183 9106040.00017.xml (accessed on 10 October 2021).

13. Freitag, M.; Kotzab, H.; Pannek, J. Dynamics in Logistics: Proceedings of the 6th International Conference LDIC 2018, Bremen, Germany; Springer: Berlin/Heidelberg, Germany, 2018.

14. Montero, J.; Finger, M. Digitalizing infrastructure: Active management for smarter networks. A Modern Guide to the Digitalization of Infrastructure; Edward Elgar Publishing: Cheltenham, UK, September 2021. Available online: https:/ / www.elgaronline.com/ view /edcoll/9781839106040/9781839106040.00007.xml (accessed on 10 October 2021). 
15. Goger, G.; Bisenberger, T. Digitalization in infrastructure construction-Developments in construction operations. Geomech. Tunn. 2020, 13, 165-177. [CrossRef]

16. Jardine, A.K.S.; Lin, D.; Banjevic, D. A review on machinery diagnostics and prognostics implementing condition-based maintenance. Mech. Syst. Signal Process. 2006, 20, 1483-1510. [CrossRef]

17. Davidsson, P.; Hajinasab, B.; Holmgren, J.; Jevinger, Å.; Persson, J.A. The Fourth Wave of Digitalization and Public Transport: Opportunities and Challenges. Sustainability 2016, 8, 1248. [CrossRef]

18. Jones, D.; Snider, C.; Nassehi, A.; Yon, J.; Hicks, B. Characterising the Digital Twin: A systematic literature review. CIRP J. Manuf. Sci. Technol. 2020, 29, 36-52. [CrossRef]

19. Grieves, M. Origins of the Digital Twin Concept. 2016. Available online: https://www.researchgate.net/publication/307509727_ Origins_of_the_Digital_Twin_Concept. (accessed on 25 September 2020).

20. Caruso, P.W.; Dumbacher, D.L. Product Lifecycle Management and the Quest for Sustainable Space Exploration Solutions. In Proceedings of the AIAA SPACE 2010 Conference and Exposition, Anaheim, CA, USA, 30 August-2 September 2010; Available online: https:/ /ntrs.nasa.gov/ citations/20110003474 (accessed on 30 August 2021).

21. Glaessgen, E.; Stargel, D. The Digital Twin Paradigm for Future NASA and U.S. Air Force Vehicles. In Proceedings of the 53rd AIAA/ASME/ASCE/AHS/ASC Structures, Structural Dynamics and Materials Conference, Honolulu, HI, USA, 23-26 April 2012. [CrossRef]

22. ARUP. Digital Twin. Towards a Meaningful Framework; ARUP: London, UK, 2019.

23. Osment, M.; Doboš, J. White Paper-Digital Twins: How to Avoid the Pitfalls of BIM. 3D Repo, White Paper. April 2021. Available online: https://3drepo.com/white-paper-digital-twins-how-to-avoid-the-pitfalls-of-bim/ (accessed on 30 August 2021).

24. Fuller, A.; Fan, Z.; Day, C.; Barlow, C. Digital Twin: Enabling Technologies, Challenges and Open Research. IEEE Access 2020, 8 , 108952-108971. [CrossRef]

25. Seppälä, L. Digital Model, Digital Shadow, or Digital Twin-What Is at the Core of Data-Driven Shipbuilding? 28 August 2020. Available online: https:/ / www.cadmatic.com/en/resources/blog/digital-model,-digital-shadow,-or-digital-twin-\%E2\%80\% 93-what-is-at-the-core-of-data-driven-shipbuilding/ (accessed on 30 August 2021).

26. Mattern, F.; Floerkemeier, C. From the internet of computers to the internet of things. In From Active Data Management to Event-Based Systems and More; Lecture Notes in Computer Science (including subseries Lecture Notes in Artificial Intelligence and Lecture Notes in Bioinformatics); Springer: Berlin/Heidelberg, Germany, 2010; Volume 6462, pp. 242-259. [CrossRef]

27. Lueth, K.L. State of the IoT 2018: Number of IoT devices now at 7B. IoT Analytics. 2018. Available online: https://iot-analytics. com/state-of-the-iot-update-q1-q2-2018-number-of-iot-devices-now-7b / (accessed on 10 August 2020).

28. IBM. Big Data Analytics. 2020. Available online: https://www.ibm.com/uk-en/analytics/hadoop/big-data-analytics (accessed on 10 August 2020).

29. Hurwitz, J.; Kirsch, D. Machine Learning Machine Learning For Dummies; Elsevier Inc.: Amsterdam, The Netherlands, 2018. [CrossRef]

30. Michalis, P. The road towards Civil Infrastructure 4.0 for proactive asset management of critical infrastructure systems. Int. Conf. Nat. Hazards Infrastruct. 2019, 2, 1-9.

31. Pu, Q.; Ananthanarayanan, G.; Bodik, P.; Kandula, S.; Akella, A.; Bahl, P.; Stoica, I. Low Latency Geo-distributed Data Analytics. Comput. Commun. Rev. 2015, 45, 421-434. [CrossRef]

32. Zhou, Z.; Chen, X.; Li, E.; Zeng, L.; Luo, K.; Zhang, J. Edge Intelligence: Paving the Last Mile of Artificial Intelligence with Edge Computing. Proc. IEEE 2019, 107, 1738-1762. [CrossRef]

33. Conejos Fuertes, P.; Martínez Alzamora, F.; Hervás Carot, M.; Alonso Campos, J.C. Building and exploiting a Digital Twin for the management of drinking water distribution networks. Urban Water J. 2020, 17, 704-713. [CrossRef]

34. Gitelman, L.D.; Kozhevnikov, M.V.; Kaplin, D.D. Asset management in grid companies using integrated diagnostic devices. Int. J. Energy Prod. Manag. 2019, 4, 230-243. [CrossRef]

35. Ji, H.; Li, J.; Zhang, S.; Wu, Q. Research on Water Resources Intelligent Management of Thermal Power Plant Based on Digital Twins. In Proceedings of the 2021 IEEE 6th International Conference on Cloud Computing and Big Data Analytics (ICCCBDA), Chengdu, China, 24-26 April 2021; pp. 557-562. [CrossRef]

36. Atalay, M.; Angin, P. A Digital Twins Approach to Smart Grid Security Testing and Standardization. In Proceedings of the 2020 IEEE International Workshop on Metrology for Industry 4.0 and IoT, Roma, Italy, 3-5 June 2020; pp. 435-440. [CrossRef]

37. AnyLogic. Alstom Develops a Rail Network Digital Twin for Railway Yard Design and Predictive Fleet Maintenance. Available online: https: / / www.anylogic.com/digital-twin-of-rail-network-for-train-fleet-maintenance-decision-support/?utm_source= white-paper\&utm_medium=link\&utm_campaign=digital-twin (accessed on 24 July 2020).

38. Fielding-Smith, M.; Gruber, P. The Digital Railway: Now Arriving on Platform 21C; SNC-Lavalin Group: Montreal, QC, Canada, 2018.

39. How Greater Anglia and Toshiba Have Used Digital Twins to Improve Timetabling. RSSB $\mid$ A Better, Safer, Railway. 28 November 2019. Available online: https://www.rssb.co.uk/what-we-do/insights-and-news/blogs/how-greater-anglia-and-toshiba-haveused-digital-twins-to-improve-timetabling (accessed on 7 October 2021).

40. Stenovec, T. How Google Maps Knows about Traffic. Tech Insider. 2015. Available online: https://www.businessinsider.com/ how-google-maps-knows-about-traffic-2015-11?r=US\&IR=T (accessed on 22 August 2020).

41. Sholli, S. Autonomous Truck Tested on A14 Upgrade in UK First. New Civil Engineer. 2019. Available online: https://www. newcivilengineer.com/latest/autonomous-truck-tested-on-a14-upgrade-in-uk-first-03-05-2019/ (accessed on 13 August 2020). 
42. Kumar, S.A.P.; Madhumathi, R.; Chelliah, P.R.; Tao, L.; Wang, S. A novel digital twin-centric approach for driver intention prediction and traffic congestion avoidance. J. Reliab. Intell. Environ. 2018, 4, 199-209. [CrossRef]

43. Brunner, P.; Denk, F.; Huber, W.; Kates, R. Virtual safety performance assessment for automated driving in complex urban traffic scenarios. In Proceedings of the 2019 IEEE Intelligent Transportation Systems Conference (ITSC), Auckland, New Zealand, 27-30 October 2019; pp. 679-685. [CrossRef]

44. Ye, C.; Butler, L.; Calka, B.; Iangurazov, M.; Lu, Q.; Gregory, A.; Girolami, M.; Middleton, C. A digital twin of bridges for structural health monitoring. In Structural Health Monitoring 2019: Enabling Intelligent Life-Cycle Health Management for Industry Internet of Things (IIOT), Proceedings of the 12th International Workshop on Structural Health Monitoring, Online, 10-12 September 2019; Stanford University: Stanford, CA, USA, 2019; Volume 1, pp. 1619-1626. [CrossRef]

45. Shim, C.; Kang, H.; Dang, N. Digital Twin Models for Maintenance of Cable-Supported Bridges. In Proceedings of the International Conference on Smart Infrastructure and Construction 2019, Cambridge, UK, 8-10 July 2019; pp. 737-742. [CrossRef]

46. NRF. Virtual Singapore. National Research Foundation Singapore. 2018. Available online: https://www.nrf.gov.sg/programmes/ virtual-singapore (accessed on 27 August 2020).

47. White, T. Newcastle's "Digital Twin" to Help City Plan for Disasters. The Guardian. 30 December 2018. Available online: https: / / www.theguardian.com/cities/2018/dec/30/newcastles-digital-twin-to-help-city-plan-for-disasters (accessed on 10 October 2021).

48. Wan, L.; Nochta, T.; Schooling, J.M. Developing a City-Level Digital Twin-Propositions and a Case Study. In Proceedings of the International Conference on Smart Infrastructure and Construction 2019, Cambridge, UK, 8-10 July 2019; pp. 187-194. [CrossRef]

49. Ford, D.N.; Wolf, C.M. Smart Cities with Digital Twin Systems for Disaster Management. J. Manag. Eng. 2020, 36, 04020027. [CrossRef]

50. Dembski, F.; Wössner, U.; Letzgus, M.; Ruddat, M.; Yamu, C. Urban Digital Twins for Smart Cities and Citizens: The Case Study of Herrenberg, Germany. Sustainability 2020, 12, 2307. [CrossRef]

51. Mohammadi, N.; Taylor, J.E. Smart city digital twins. In Proceedings of the 2017 IEEE Symposium Series on Computational Intelligence (SSCI), Honolulu, HI, USA, 27 November-1 December 2017; pp. 1-5. [CrossRef]

52. Francisco, A.; Mohammadi, N.; Taylor, J.E. Smart City Digital Twin-Enabled Energy Management: Toward Real-Time Urban Building Energy Benchmarking. J. Manag. Eng. 2020, 36, 04019045. [CrossRef]

53. Kumar, H.; Singh, M.K.; Gupta, M.P. Smart mobility: Crowdsourcing solutions for smart transport system in smart cities context. In Proceedings of the 11th International Conference on Theory and Practice of Electronic Governance, Galway, Ireland, 4-6 April 2018; Association for Computing Machinery: New York, NY, USA, April 2018; pp. 482-488. [CrossRef]

54. Rudskoy, A.; Ilin, I.; Prokhorov, A. Digital Twins in the Intelligent Transport Systems. Transp. Res. Procedia 2021, 54, 927-935. [CrossRef]

55. Highways England. Connected and Autonomous Plant Roadmap to 2035; National Highways: Birmingham, UK, 2020 ; pp. 1-64.

56. Yurkevich, E.V.; Stepanovskaya, I.A. Controlling the security of the airport airspace using the digital twin. J. Phys. Conf. Ser. 2021, 1864, 012128. [CrossRef]

57. Saifutdinov, F.; Jackson, I.; Tolujevs, J.; Zmanovska, T. Digital Twin as a Decision Support Tool for Airport Traffic Control. In Proceedings of the 2020 61st International Scientific Conference on Information Technology and Management Science of Riga Technical University (ITMS), Riga, Latvia, 15-16 October 2020; pp. 1-5. [CrossRef]

58. Lu, R.; Brilakis, I. Digital twinning of existing reinforced concrete bridges from labelled point clusters. Autom. Constr. 2019, 105, 102837. [CrossRef]

59. Kaewunruen, S.; Xu, N. Digital Twin for Sustainability Evaluation of Railway Station Buildings. Front. Built Environ. 2018,4 , 77. [CrossRef]

60. Pedersen, A.N.; Borup, M.; Brink-Kjær, A.; Christiansen, L.E.; Mikkelsen, P.S. Living and Prototyping Digital Twins for Urban Water Systems: Towards Multi-Purpose Value Creation Using Models and Sensors. Water 2021, 13, 592. [CrossRef]

61. Curl, J.M.; Nading, T.; Hegger, K.; Barhoumi, A.; Smoczynski, M. Digital Twins: The Next Generation of Water Treatment Technology. J. AWWA 2019, 111, 44-50. [CrossRef]

62. Xiangdong, X.; Bo, L.; Jiannan, G. Asset management of oil and gas pipeline system Based on Digital Twin. IFAC-PapersOnLine 2020, 53, 715-719. [CrossRef]

63. Bhowmik, S. Digital Twin of Subsea Pipelines: Conceptual Design Integrating IoT, Machine Learning and Data Analytics. In Proceedings of the Offshore Technology Conference, Houston, TX, USA, 6-9 May 2019. [CrossRef]

64. Jain, P.; Poon, J.; Singh, J.P.; Spanos, C.; Sanders, S.R.; Panda, S.K. A Digital Twin Approach for Fault Diagnosis in Distributed Photovoltaic Systems. IEEE Trans. Power Electron. 2020, 35, 940-956. [CrossRef]

65. Therrien, J.-D.; Nicolaï, N.; Vanrolleghem, P.A. A critical review of the data pipeline: How wastewater system operation flows from data to intelligence. Water Sci. Technol. 2020, 82, 2613-2634. [CrossRef]

66. Carvalho, W.O. BIM and AM to Manage Critical and Relevant Water and Wastewater Utilities Assets. In Proceedings of the 18th International Conference on Computing in Civil and Building Engineering, São Paulo, Brazil, 18-20 August 2020; pp. 697-720. [CrossRef]

67. Ghandar, A.; Ahmed, A.; Zulfiqar, S.; Hua, Z.; Hanai, M.; Theodoropoulos, G. A Decision Support System for Urban Agriculture Using Digital Twin: A Case Study with Aquaponics. IEEE Access 2021, 9, 35691-35708. [CrossRef] 
68. Seilov, S.Z.; Kuzbayev, A.T.; Seilov, A.A.; Shyngisov, D.S.; Goikhman, V.Y.; Levakov, A.K.; Sokolov, N.A.; Zhursinbek, Y.S. The Concept of Building a Network of Digital Twins to Increase the Efficiency of Complex Telecommunication Systems. Complexity 2021, 2021, e9480235. [CrossRef]

69. Deng, J.; Zheng, Q.; Liu, G.; Bai, J.; Tian, K.; Sun, C.; Yan, Y.; Liu, Y. A Digital Twin Approach for Self-optimization of Mobile Networks. In Proceedings of the 2021 IEEE Wireless Communications and Networking Conference Workshops (WCNCW), Nanjing, China, 29 March 2021; pp. 1-6. [CrossRef]

70. Hu, C.; Fan, W.; Zen, E.; Hang, Z.; Wang, F.; Qi, L.; Alam Bhuiyan, Z. A Digital Twin-Assisted Real-time Traffic Data Prediction Method for 5G-enabled Internet of Vehicles. IEEE Trans. Ind. Inform. 2021. [CrossRef]

71. Shangguan, D.; Chen, L.; Ding, J. A Digital Twin-Based Approach for the Fault Diagnosis and Health Monitoring of a Complex Satellite System. Symmetry 2020, 12, 1307. [CrossRef]

72. Wang, Z.; Liao, X.; Zhao, X.; Han, K.; Tiwari, P.; Barth, M.J.; Wu, G. A Digital Twin Paradigm: Vehicle-to-Cloud Based Advanced Driver Assistance Systems. In Proceedings of the 2020 IEEE 91st Vehicular Technology Conference (VTC2020-Spring), Antwerp, Belgium, 25-28 May 2020; pp. 1-6. [CrossRef]

73. Meža, S.; Mauko Pranjić, A.; Vezočnik, R.; Osmokrović, I.; Lenart, S. Digital Twins and Road Construction Using Secondary Raw Materials. J. Adv. Transp. 2021, 2021, e8833058. [CrossRef]

74. Ranjbar, R.; Duviella, E.; Etienne, L.; Maestre, J.-M. Framework for a digital twin of the Canal of Calais. Procedia Comput. Sci. 2020, 178, 27-37. [CrossRef]

75. Chen, Z.; Huang, L. Digital Twin in Circular Economy: Remanufacturing in Construction. IOP Conf. Ser. Earth Environ. Sci. 2020, 588, 032014. [CrossRef]

76. Kritzinger, W.; Karner, M.; Traar, G.; Henjes, J.; Sihn, W. Digital Twin in manufacturing: A categorical literature review and classification. IFAC-PapersOnLine 2018, 51, 1016-1022. [CrossRef]

77. Kessler, H. Getting under the Surface of Our National Underground Assets Register (NUAR) Team. Geospatial Commission. 2019. Available online: https://geospatialcommission.blog.gov.uk/2019/12/18/getting-under-the-surface-of-our-nationalunderground-assets-register-nuar-team/ (accessed on 22 August 2020).

78. Bolton, A.; Enzer, M.; Schooling, J. The Gemini Principles; University of Cambridge: Cambridge, UK, 2018; p. 15. [CrossRef]

79. BBC. Pakistan Works on Power Blackout after "Rebel Attack". BBC News. 2015. Available online: https://www.bbc.co.uk/news/ world-asia-30981338 (accessed on 28 August 2020).

80. Hetherington, J.; West, M. The pathway towards an Information Management Framework—A “Commons” for Digital Built Britain; Centre for Digital Built Britain: Cambridge, UK, 2020; p. 58. [CrossRef]

81. Centre for Digital Built Britain. The Approach to Delivering a National Digital Twin for the United Kingdom; Centre for Digital Built Britain: Cambridge, UK, 2020.

82. Walters, A. CDBB Officially Launches the Digital Twin Hub | Centre for Digital Built Britain. 2020. Available online: https: //www.cdbb.cam.ac.uk/news/cdbb-officially-launches-digital-twin-hub (accessed on 9 September 2020).

83. HM Treasury. Chancellor Launches Comprehensive Spending Review. 2020. Available online: https://www.gov.uk/government/ news / chancellor-launches-comprehensive-spending-review (accessed on 9 September 2020). 